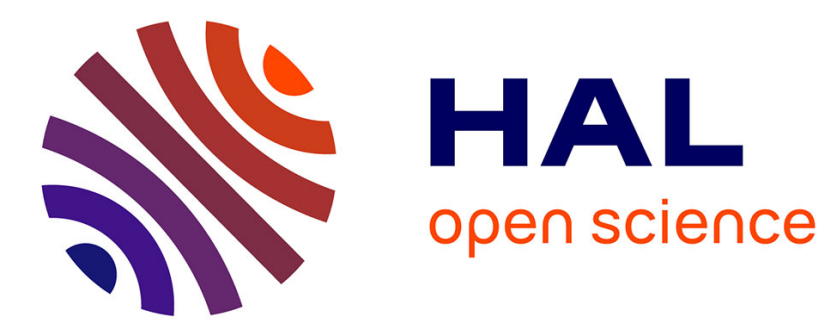

\title{
Seasonal changes in Saturn's stratosphere inferred from Cassini/CIRS limb observations
}

\author{
M Sylvestre, S Guerlet, T Fouchet, A Spiga, F.M. Flasar, B Hesman, G.L.
} Bjoraker

\section{- To cite this version:}

M Sylvestre, S Guerlet, T Fouchet, A Spiga, F.M. Flasar, et al.. Seasonal changes in Saturn's stratosphere inferred from Cassini/CIRS limb observations. Icarus, 2015, 258, pp.224-238. 10.1016/j.icarus.2015.05.025 . hal-01172604

\section{HAL Id: hal-01172604 https://hal.sorbonne-universite.fr/hal-01172604}

Submitted on 7 Jul 2015

HAL is a multi-disciplinary open access archive for the deposit and dissemination of scientific research documents, whether they are published or not. The documents may come from teaching and research institutions in France or abroad, or from public or private research centers.
L'archive ouverte pluridisciplinaire HAL, est destinée au dépôt et à la diffusion de documents scientifiques de niveau recherche, publiés ou non, émanant des établissements d'enseignement et de recherche français ou étrangers, des laboratoires publics ou privés. 


\title{
Seasonal changes in Saturn's stratosphere inferred from Cassini/CIRS limb observations
}

\author{
M. Sylvestre ${ }^{a, b, c, *}$, S. Guerlet ${ }^{\mathrm{b}, \mathrm{c}}$, T. Fouchet ${ }^{\mathrm{a}, \mathrm{c}}$, A. Spiga ${ }^{\mathrm{b}, \mathrm{c}}$, F. M. Flasar ${ }^{\mathrm{d}}$, B. Hesman ${ }^{\mathrm{e}}$, G. L. Bjoraker ${ }^{\mathrm{d}}$ \\ ${ }^{a}$ LESIA, Observatoire de Paris, CNRS, UPMC, Université Paris-Diderot, 5 place Jules Janssen, 92195 Meudon, France \\ ${ }^{b}$ CNRS, LMD, IPSL, UMR 8539, 4 Place Jussieu, F-75005, Paris, France \\ ${ }^{c}$ Sorbonne Universités, UPMC Paris 06, UMR 8109, F-75005 Paris, France \\ ${ }^{d}$ NASA Goddard Space Flight Center, Greenbelt, MD 20771, USA \\ ${ }^{e}$ Department of Astronomy, University of Maryland, College Park, MD 20742, USA
}

\begin{abstract}
We present temperature and hydrocarbons abundances $\left(\mathrm{C}_{2} \mathrm{H}_{6}, \mathrm{C}_{2} \mathrm{H}_{2}, \mathrm{C}_{3} \mathrm{H}_{8}\right)$ retrieved from Cassini/CIRS limb spectra, acquired during northern spring in $2010\left(L_{S}=12^{\circ}\right)$ and $2012\left(L_{S}=31^{\circ}\right)$. We compare them to the previous limb measurements performed by Guerlet et al. (2009) during northern winter. The latitudinal coverage (from $79^{\circ} \mathrm{N}$ to $70^{\circ} \mathrm{S}$ ) and the sensitivity of our observations to a broad range of pressure levels (from $20 \mathrm{hPa}$ to $0.003 \mathrm{hPa}$ ) allow us to probe the meridional and vertical structure of Saturn's stratosphere during northern spring. Our results show that in the northern hemisphere, the lower stratosphere $(1 \mathrm{hPa})$ has experienced the strongest warming from northern winter to spring $\left(11 \pm_{0.9}^{1.1} \mathrm{~K}\right)$, while the southern hemisphere exhibits weak variations of temperature at the same pressure level. We investigate the radiative contribution in the thermal seasonal evolution by comparing these results to the radiativeconvective model of Guerlet et al. (2014). We show that radiative heating and cooling by atmospheric minor constituents is not always sufficient to reproduce the measured variations of temperature (depending on the pressure level). The measurements of the hydrocarbons abundances and their comparison with the predictions of the 1D photochemical model of Moses and Greathouse (2005) give insights into large scale atmospheric dynamics. At $1 \mathrm{hPa}, \mathrm{C}_{2} \mathrm{H}_{6}, \mathrm{C}_{2} \mathrm{H}_{2}$, and $\mathrm{C}_{3} \mathrm{H}_{8}$ abundances are remarkably constant from northern winter to spring. At the same pressure level, $\mathrm{C}_{2} \mathrm{H}_{6}$ and $\mathrm{C}_{3} \mathrm{H}_{8}$ exhibit homogeneous meridional distributions unpredicted by this photochemical model, unlike $\mathrm{C}_{2} \mathrm{H}_{2}$. This is consistent with the existence of a meridional circulation at $1 \mathrm{hPa}$, as suggested by previous studies.
\end{abstract}

\section{Introduction}

Saturn's atmosphere features significant seasonal variations in insolation owing to its obliquity of $26.7^{\circ}$, enhanced by its eccentric orbit $(e=0.056)$, and by the shadow of the rings on the planet. Hence, pronounced seasonal and hemispheric contrasts in thermal structure, chemistry, and dynamics of the atmosphere are expected. These changes can be quite intricate, especially in the stratosphere where radiative and photochemical timescales can be of the same order as Saturn's orbital period. This region hosts the photolysis of methane $\left(\mathrm{CH}_{4}\right)$, which is the first reaction of a chain producing various hydrocarbons such as ethane $\left(\mathrm{C}_{2} \mathrm{H}_{6}\right)$, acetylene $\left(\mathrm{C}_{2} \mathrm{H}_{2}\right)$, or propane $\left(\mathrm{C}_{3} \mathrm{H}_{8}\right)$. The variations of solar energy deposition influences the photochemical production and loss rates. As a result, vertical, meridional, and seasonal gradients of composition are expected to be significant (Moses and Greathouse, 2005). Atmospheric composition also affects Saturn's thermal structure (through radiative balance between solar energy deposition and thermal

\footnotetext{
* Corresponding author

Email address: melody.sylvestre@obspm.fr (M. Sylvestre)
}

infrared emission), which in turn affects the dynamics. Monitoring the seasonal variations in temperature and composition allows us to characterize the sensitivity of Saturn's atmosphere to insolation changes, and to better understand the different interactions between photochemistry, radiative balance, and dynamics.

Before the arrival of the Cassini spacecraft in 2004, orbital measurements and ground-based observations have provided sparse information about seasonal changes on Saturn. From Voyager 1/IRIS observations, Hanel et al. (1981) inferred that southern mid-latitudes are warmer by $5 \mathrm{~K}$ than northern mid-latitudes at $209 \mathrm{hPa}^{1}$ just after the northern spring equinox $\left(L_{S}=9^{\circ}\right)$. This is consistent with the predictions of the radiative model of Carlson et al. (1980). Orton and Yanamandra-Fisher (2005) performed Keck I/LWS observations in February 2004, during southern summer $\left(L_{S}=288^{\circ}\right)$. Their results show that stratospheric temperatures at $3 \mathrm{hPa}$ increase from equator to $70^{\circ} \mathrm{S}$ by $8 \mathrm{~K}$, consistently with seasonal forcing and general trends predicted by the time-dependent radiative model of Bézard and Gautier

\footnotetext{
${ }^{1} 1 \mathrm{hPa}=1 \mathrm{mbar}$
} 
(1985). Nevertheless, Orton and Yanamandra-Fisher (2005) also found a steep temperature increase poleward of $70^{\circ} \mathrm{S}$, which is not reproduced by this model.

The duration of the Cassini mission from 2004 to 2017 (as recently extended) opens new perspectives to study Saturn's seasonal variations. Fletcher et al. (2010) studied the seasonal changes between 2004 and 2009 (from northern winter to spring equinox) in the $[75 ; 800] \mathrm{hPa}$ and $[0.5 ; 5.0] \mathrm{hPa}$ ranges (upper troposphere and lower stratosphere) with Cassini/CIRS (Composite InfraRed Spectrometer) nadir observations. These authors demonstrated that, in the stratosphere, northern mid-latitudes warm (by $9 \mathrm{~K}$ at $35^{\circ} \mathrm{N}, 1 \mathrm{hPa}$ ) from winter to spring, as they emerge from the shadow of the rings. In the same time, the southern hemisphere cools within the south polar hood (by $8 \mathrm{~K}$ at $70^{\circ} \mathrm{S}, 1 \mathrm{hPa}$ ).

Ethane $\left(\mathrm{C}_{2} \mathrm{H}_{6}\right)$ and acetylene $\left(\mathrm{C}_{2} \mathrm{H}_{2}\right)$ are the two main photochemical by-products and coolants in Saturn's stratosphere. Their globally averaged abundances have been measured since Voyager observations (Courtin et al., 1984), but the study of their meridional and seasonal variations began quite recently. Ground-based observations with IRTF/TEXES (Greathouse et al., 2005) and Cassini/CIRS limb (Guerlet et al., 2009) and nadir soundings (Howett et al., 2007; Hesman et al., 2009) show that at $1 \mathrm{hPa}$ and $2 \mathrm{hPa}$ the meridional distribution of ethane is homogeneous, whereas the distribution of acetylene is decreasing from equator to poles. This behaviour is not predicted by photochemical models such as the 1D seasonal model of Moses and Greathouse (2005), and suggests a meridional transport which affects the distribution of ethane. Cassini/CIRS limb observations of 2005 and 2006 (winter in the northern hemisphere, $L_{S}=303^{\circ}-339^{\circ}$, Guerlet et al. (2009)) also showed that at pressures inferior to $0.1 \mathrm{hPa}$, ethane and acetylene are more abundant in the northern hemisphere than in the southern one, which cannot be explained by photochemistry alone. Guerlet et al. (2009) interpreted this behaviour as an effect of a strong meridional circulation from summer to winter hemisphere. Sinclair et al. (2013) studied the seasonal variations of ethane and acetylene between 2005 and 2010 (from $L_{S}=308^{\circ}$ to $L_{S}=15^{\circ}$ ). They used Cassini/CIRS nadir observations to probe the abundances of these hydrocarbons at $2 \mathrm{hPa}$. They measured surprising variations in hydrocarbons abundances, stronger for ethane than for acetylene. Indeed, they noticed an enrichment in hydrocarbons at $25^{\circ} \mathrm{N}$ (by $29 \%$ for ethane) and a depletion at $15^{\circ} \mathrm{S}$ (by $17 \%$ for ethane), which they attributed respectively to localised downwelling and upwelling. Their results also show a global increase of the abundances of northern hemisphere. Sinclair et al. (2013) suggested that an extensive downwelling or a general hemisphere to hemisphere circulation may be at play.
Propane $\left(\mathrm{C}_{3} \mathrm{H}_{8}\right)$ is the most abundant $\mathrm{C}_{3}$ molecule in Saturn's atmosphere. Greathouse et al. (2006) detected it for the first time in Saturn's southern hemisphere, using IRTF/TEXES observations at the southern summer solstice $\left(L_{S}=270^{\circ}\right)$. They measured a similar abundance of propane at $20^{\circ} \mathrm{S}$ and $80^{\circ} \mathrm{S}$ at $5 \mathrm{hPa}$. Sinclair et al. (2014) presented a comparison between Voyager/IRIS (in 1980, $L_{S}=8^{\circ}$ ) and Cassini/CIRS (in 2009 and 2010, $L_{S}=3^{\circ}$ and $L_{S}=14^{\circ}$ ) observations to measure the interannual variability of temperature, ethane and acetylene abundances in Saturn's stratosphere (in the $[100 ; 200] \mathrm{hPa}$ range and at $2.1 \mathrm{hPa}$ ). Their results show a higher acetylene concentration at $25^{\circ} \mathrm{S}$ in 1980 than in 2009-2010, and a colder temperature in 1980 at the equator than in 2009-2010. Sinclair et al. (2014) attributed these differences to different phases of Saturn's equatorial oscillation (temperature oscillation propagating downward in the equatorial zone, Fouchet et al. (2008); Orton et al. (2008)).

In this study, we present temperature, ethane, acetylene, and propane vertical profiles along with their meridional distributions obtained by Cassini/CIRS limb observations performed from 2010 to 2012 . We investigate the seasonal changes in Saturn's atmosphere between 2005 and 2012 by comparing these observations and previous limb observations (acquired from 2005 to 2007), analysed by Guerlet et al. (2009). The use of the same instrument and the same retrieval algorithm ensures the high consistency of our analysis with the one of Guerlet et al. (2009). Limb data allow us to probe larger pressure ranges $(20-0.003 \mathrm{hPa}$ for temperature and 3-0.01 hPa for hydrocarbons) than nadir data, so we complete the results of Fletcher et al. (2010) and Sinclair et al. (2013) by probing more extensively the vertical structure of the stratosphere. Our latitudinal coverage (from $79^{\circ} \mathrm{N}$ to $70^{\circ} \mathrm{S}$ ) samples comprehensively the meridional structure of the atmosphere, especially at mid and high northern latitudes which are not probed in Guerlet et al. (2009). The measured temperature variations are compared to the predictions of the radiative-convective model of Guerlet et al. (2014) in order to identify the radiative contribution in the observed evolution of the atmosphere, and to explore the possible processes at play in the behaviour of Saturn's atmosphere in response to the seasonal insolation variations. We also compare the retrieved abundances of ethane, acetylene, and propane to the previous retrievals of Guerlet et al. (2009), and compare them to the predictions of the 1D seasonal photochemical model of Moses and Greathouse (2005) to get insights on the processes governing their distributions. In Section 2, we detail the characteristics of our observations and of our retrieval algorithm. In Section 3, we present our results and their comparison with previous measurements. We provide a discussion about the possible phenomena which could explain the measured seasonal variations in the Section 4. 


\begin{tabular}{lcccc}
\hline Name & Date & Solar longitude & Latitudinal coverage & Spectral resolution $\left(\mathrm{cm}^{-1}\right)$ \\
\hline LIMBINT001_PRIME* $^{*}$ & $13 / 02 / 2010$ & $7^{\circ}$ & $15^{\circ} \mathrm{N}, 20^{\circ} \mathrm{N}$ & 7.5 \\
LIMBINTB001_PRIME* $^{\circ}$ & $13 / 02 / 2010$ & $7^{\circ}$ & $5^{\circ} \mathrm{N}, 10^{\circ} \mathrm{N}$ & 7.5 \\
LIMBINTC001_PRIME* $^{\circ}$ & $13 / 02 / 2010$ & $7^{\circ}$ & $5^{\circ} \mathrm{S}$ to $20^{\circ} \mathrm{S}$ & 7.5 \\
LIMBINT001_PRIME & $23 / 09 / 2010$ & $12^{\circ}$ & $25^{\circ} \mathrm{N}$ to $80^{\circ} \mathrm{N}$ & 7.5 \\
LIMBMAP001_PIE & $04 / 01 / 2012$ & $29^{\circ}$ & $70^{\circ} \mathrm{S}$ & 7.5 \\
LIMBMAP001_PIE & $04 / 01 / 2012$ & $29^{\circ}$ & $35^{\circ} \mathrm{S}$ & 7.5 \\
ALPCMAOCC001_VIMS & $21 / 02 / 2012$ & $31^{\circ}$ & $50^{\circ} \mathrm{S}$ and $55^{\circ} \mathrm{S}$ & 7.5 \\
ALPHYAOCC001_VIMS & $21 / 02 / 2012$ & $31^{\circ}$ & $42^{\circ} \mathrm{S}$ and $47^{\circ} \mathrm{S}$ & \\
\hline
\end{tabular}

Table 1: List and characteristics of the CIRS limb datasets analysed in this study. The asterisk denotes data for which retrieved temperature profiles had already been presented (Guerlet et al., 2011). We do not have data in 2011, as orbits of the Cassini spacecraft were not fitted for limb observations.
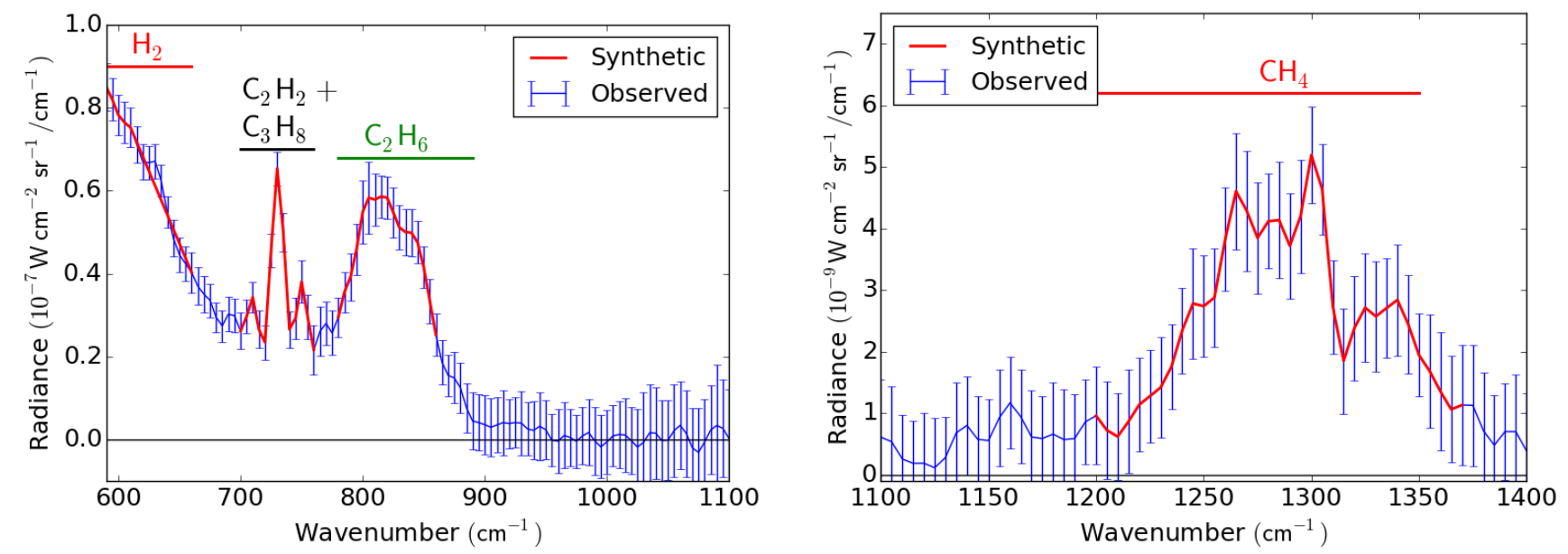

Figure 1: Example of co-added CIRS spectra (in blue) acquired at $30^{\circ} \mathrm{N}$ by FP3 (left) and FP4 (right) acquired respectively at altitudes of $180 \mathrm{~km}(8.4 \mathrm{hPa})$ and $305 \mathrm{~km}(0.7 \mathrm{hPa})$. Both spectra have a spectral resolution of $7.5 \mathrm{~cm}^{-1}$. Red lines stand for the synthetic spectra calculated during the retrieval process.

\section{Data Analysis}

\subsection{Observations}

CIRS (Flasar et al., 2004) is a thermal infrared Fourier transform spectrometer with three focal planes that cover spectral ranges from $10 \mathrm{~cm}^{-1}$ to $1400 \mathrm{~cm}^{-1}(7 \mu \mathrm{m}$ to $1 \mathrm{~mm})$. In this study, we exploit spectra acquired simultaneously by the focal planes FP3 $\left(600-1100 \mathrm{~cm}^{-1}\right)$ and FP4 $\left(1100-1400 \mathrm{~cm}^{-1}\right)$ at unapodized spectral resolutions of $7.5 \mathrm{~cm}^{-1}$ and $0.5 \mathrm{~cm}^{-1}$. FP3 and FP4 each contain 10 detectors with an angular resolution of $0.273 \mathrm{mrad}$ corresponding, in limb viewing geometry, to a vertical resolution of 1-2 Saturn's scale height (50-100 $\mathrm{km}$ ) on the planet (varying with the distance between Cassini and Saturn).

Table 1 presents the different datasets analysed in this study. They cover latitudes from $80^{\circ} \mathrm{N}$ to $70^{\circ} \mathrm{S}$, thus they provide an overview of the atmosphere in both hemispheres. Temperature retrieved from the February 2010 datasets is already presented in Guerlet et al. (2011), so we retrieve only hydrocarbons abundances in these datasets, with the exact same algorithm as these authors (see section 2.3.1). The datasets covering the northern hemisphere were acquired before the Great White Storm of 2010-2011 (Sánchez-Lavega et al., 2012), and the outbreak of the "beacon" (warm stratospheric vortex, Fletcher et al. (2012)). Hence, our measurements of seasonal variations are not affected by these two events. Measurements are carried out in limb geometry, where the parallel arrays of FP3 and FP4 are set perpendicular to the limb of the planet, and each detector sounds a different tangent height. In this geometry, the length of the line of sight is larger than in nadir geometry, which makes the instrument sensitive to temperature and trace species at higher altitudes, and over a broader pressure range (from $20 \mathrm{hPa}$ to $0.003 \mathrm{hPa}$ for temperature and from $3 \mathrm{hPa}$ to $0.01 \mathrm{hPa}$ for hydrocarbons) than with nadir geometry. Each limb observation is composed of two acquisition sequences targeting the same latitude but different altitudes to optimize the vertical coverage of the measurements. Each acquisition sequence lasts between $430 \mathrm{~s}$ to $1050 \mathrm{~s}$ while 45 to 110 spectra are collected per detector and per sequence. We use the photometric calibration provided by the Cassini/CIRS team (version 3.2, Conor A. Nixon and Team (2012)) to correct the 
noise induced by the sky background and the thermal noise of the detectors. When the measured radiance is weaker than the noise (e.g. between $1000 \mathrm{~cm}^{-1}$ and $1100 \mathrm{~cm}^{-1}$ ), this calibration process sometimes gives negative radiances.

For each sequence, the spectra acquired by each detector are co-added to obtain a single spectrum per sequence and per detector, and to increase the signal to noise ratio by $\sqrt{n}$ (with $n$ the number of acquired spectra). The signal to noise ratio reaches 250 at $600 \mathrm{~cm}^{-1}$ (FP3) and 70 at $1300 \mathrm{~cm}^{-1}$ (FP4). For each latitude, we have a set of 20 unapodized co-added spectra (corresponding to the 20 detectors) sampling the vertical structure of Saturn's stratosphere. The temperature and hydrocarbons abundances retrievals are performed on these sets of co-added spectra. Figure 1 shows examples of co-added spectra acquired by FP3 and FP4 for latitude $30^{\circ} \mathrm{N}$, at $L_{S}=12^{\circ}$, and at respective corrected altitudes of $180 \mathrm{~km}$ and $305 \mathrm{~km}$ (the altitude correction is detailed in section 2.3.1).

The altitudes determined by the navigation of the spacecraft are not precise enough for our retrievals. Indeed, their calculation depends on the NAIF (Navigation and Ancillary In-Formation) reference ellipsoid, which is an approximation to the real shape of the planet. This produces an offset up to $\sim 150 \mathrm{~km}$ between real and tabulated altitudes in the database, depending on latitude. Pointing errors can also shift the altitudes by $\lesssim 20 \mathrm{~km}$. Our retrieval scheme corrects for these altitude errors, as explained in section 2.3.1.

\subsection{Treatment of ALPCMAOCC001_VIMS and $A L$ - PHYAOCC001_VIMS datasets}

An additional treatment is required for the datasets ALPCMAOCC001_VIMS and ALPHYAOCC001_VIMS, at the latitudes $42^{\circ} \mathrm{S}$ and $50^{\circ} \mathrm{S}$. We notice a clear decrease of the measured flux over time during the observations. An example is shown in fig. 2, where the mean radiance at $600 \mathrm{~cm}^{-1}$ of a single detector is plotted against time. It is unlikely that this radiance variation is caused by a temperature variation in longitude. Indeed, the brightness temperature difference needed for the radiance decrease presented in fig. 2 (from $1 \times 10^{-7} \mathrm{~W} / \mathrm{cm}^{2} / \mathrm{sr} / \mathrm{cm}^{-1}$ to $\left.0.3 \times 10^{-7} \mathrm{~W} / \mathrm{cm}^{2} / \mathrm{sr} / \mathrm{cm}^{-1}\right)$ is $15 \mathrm{~K}$ at $600 \mathrm{~cm}^{-1}$. Such a longitudinal temperature variation has only been measured during the Great White Storm of 2010-2011, where warm disturbances (named "beacons") were observed in the stratosphere (Fletcher et al., 2012). This effect is more likely caused by a lack of pointing stability during the observations, which results in a vertical drift of each detector during the acquisition of the spectra. To correct for this effect, we divide the affected sequences of observations into several smaller sub-sequences. In these sub-sequences the standard deviation of the radiances at $600 \mathrm{~cm}^{-1}$ is similar to the standard deviation of the radiances measured at the same wavenumber in observations sequences unaffected by this altitude drift. The $600 \mathrm{~cm}^{-1}$ wavenumber is selected because at this wavenumber the flux is larger than measurement noise, as it is within the spectral range of the hydrogen collision induced emission (see section 2.3.1). We co-add the spectra of each sub-sequence instead of using the whole sequence.

Besides, these datasets were not acquired in the limb geometry presented in section 2.1 (at all latitudes). The detectors arrays were tilted with respect to the local vertical, as shown on fig. 3 . The tilt angle varies between $23^{\circ}$ and $29^{\circ}$ depending on the observed latitude. This effect requires a special treatment during the retrieval of temperature and hydrocarbons abundances, which is presented in section 2.3.2.

\subsection{Retrieval algorithm}

\subsubsection{Method}

We retrieve temperature and hydrocarbons abundance profiles for each latitude using the regularized and constrained linear inversion method described in Rodgers (2000), coupled with a forward radiative transfer model. We use the exact same algorithm as in Guerlet et al. (2009) in order to ensure a consistent comparison between the two studies.

Our radiative transfer model uses spherical geometry, using the osculating radius at the latitude of the retrieval. It computes synthetic spectra in the spectral domain suitable for the retrieved physical quantity (temperature or hydrocarbons abundances). The opacities of the gases included in this model are available in the spectroscopic database GEISA 2009 (Jacquinet-Husson et al., 2005, 2008). For temperature retrievals, synthetic spectra are calculated in the spectral domains $[590 ; 660] \mathrm{cm}^{-1}$ and $[1200 ; 1370] \mathrm{cm}^{-1}$. In the first spectral domain, the dominant contribution to the radiance is the hydrogen collisions $\left(\mathrm{H}_{2}-\mathrm{H}_{2}\right.$ and $\left.\mathrm{H}_{2}-\mathrm{He}\right)$ induced emission $\left([590 ; 660] \mathrm{cm}^{-1}\right.$, Borysow et al. (1985); Borysow and Frommhold (1986); Borysow et al. (1988)), which intensity is very sensitive to lower stratospheric temperature. We set the $[\mathrm{He}] /\left[\mathrm{H}_{2}\right]$ ratio at 0.1355 , determined by Conrath and Gautier (2000). The opacities of acetylene, methylacetylene $\left(\mathrm{CH}_{3} \mathrm{C}_{2} \mathrm{H}\right)$ and diacetylene $\left(\mathrm{C}_{4} \mathrm{H}_{2}\right)$ are also included in our radiative transfer code, as they contribute weakly to the radiance in the $[590 ; 660] \mathrm{cm}^{-1}$ range. Their abundance profiles are fixed to those predicted by the model of Moses and Greathouse (2005). The spectral domain $[1200 ; 1370] \mathrm{cm}^{-1}$ matches the $\nu_{4}$ emission band of methane. As $\mathrm{H}_{2}$ and $\mathrm{He}$, this gas is homogeneously distributed in Saturn's atmosphere, thus it can be used to perform temperature measurements. The volume mixing 


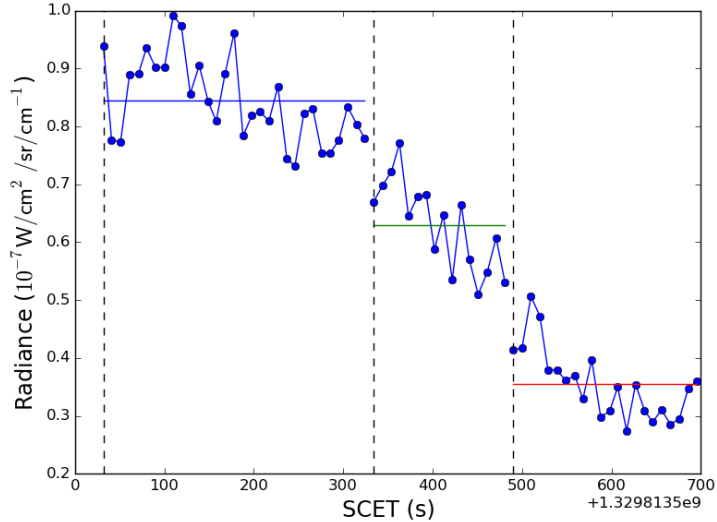

Figure 2: Evolution of the measured flux at $600 \mathrm{~cm}^{-1}$ during the observation sequence at $42^{\circ} \mathrm{S}$. SCET stands for SpaceCraft Event Time. Vertical dashed lines delimit the chosen sub-sequences. Horizontal lines represent the mean flux of each sub-sequence.

ratio of $\mathrm{CH}_{4}$ is set to the value determined by Flasar et al. $(2005): 4.5 \times 10^{-3}$. We use the vertical profile of $\mathrm{CH}_{4}$ predicted by the model of Moses et al. (2000). The weak radiative contributions of acetylene and $\mathrm{CH}_{3} \mathrm{D}$ are included in the calculation of the synthetic spectra in the $[1200 ; 1370] \mathrm{cm}^{-1}$ range. We set the abundance of $\mathrm{CH}_{3} \mathrm{D}$ using the ratio $\left[\mathrm{CH}_{3} \mathrm{D}\right] /\left[\mathrm{CH}_{4}\right]=1.7 \times 10^{-5}$, determined by Lellouch et al. (2001). For ethane abundances retrievals, the spectral domain $[780 ; 860] \mathrm{cm}^{-1}$ is selected, since the radiance in this spectral domain is dominated by the $\nu_{9}$ band of this gas (centered at $822 \mathrm{~cm}^{-1}$ ). Nevertheless, as the wings of the $\nu_{5}$ band of acetylene (centered at $729 \mathrm{~cm}^{-1}$ ) contributes weakly to the radiance in this region, we set its vertical abundance profile to the prediction of the model of Moses and Greathouse (2005). The last selected spectral domain is $[700 ; 760] \mathrm{cm}^{-1}$, which is used to retrieve acetylene and propane. The acetylene $\nu_{5}$ band is the dominant spectral feature in this domain but the $\nu_{21}$ band of propane (centered at $748 \mathrm{~cm}^{-1}$ ) contributes significantly to the radiance, even if the spectral resolution of the observations is not fine enough to isolate it. Examples of synthetic spectra calculated in the different spectral bands presented above are shown in fig. 1.

The sensitivity of our measurements to the different retrieved physical quantities is given by the kernels or functional derivatives $K_{i j}=\frac{\partial I_{i}}{\partial x_{j}}$, where $I_{i}$ is the measured radiance at the wavenumber $\sigma_{i}$, and $x_{j}$ a retrieved parameter (temperature or hydrocarbon abundance) at the pressure level $p_{j}$. The left panel of fig. 4 shows the temperature kernels $K_{i j}=\frac{\partial I_{i}}{\partial T_{j}}$ as a function of pressure, for nine probed altitudes, at $1305 \mathrm{~cm}^{-1}$ (where the opacity of the $\mathrm{CH}_{4} \nu_{4}$ band is the highest), and at $605 \mathrm{~cm}^{-1}$ (in the hydrogen collisions induced emission) at $50^{\circ} \mathrm{N}$. The right panel of fig. 4 shows the ethane abundance kernels

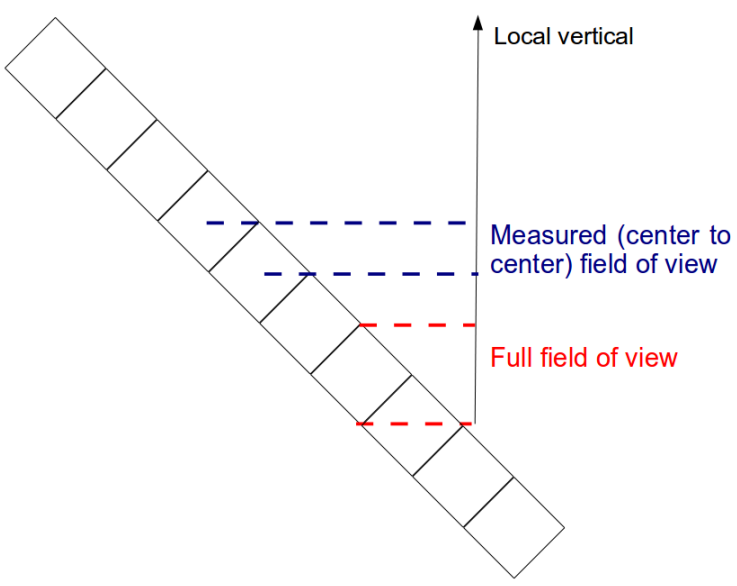

Figure 3: Observations geometry in the ALPCMAOCC001_VIMS and ALPHYAOCC001_VIMS datasets and tested fields of view.

$K_{i j}=\frac{\partial I_{i}}{\partial q_{j}}$ as a function of pressure, for five probed altitudes, at $815 \mathrm{~cm}^{-1}$ (at the center of ethane $\nu_{9}$ band), at $50^{\circ} \mathrm{N}$. The temperature and ethane kernels presented in this figure are representative examples of the kernels obtained for the datasets presented in this study. The two spectral bands used for the temperature retrievals are complementary, as they allow us to probe the temperature from $20 \mathrm{hPa}$ to $0.003 \mathrm{hPa}$. Ethane abundances are probed in the $[3 ; 0.01] \mathrm{hPa}$ range. Acetylene kernels are similar to ethane kernels, thus the sensitivity limits for acetylene abundances retrievals are the same as those presented for ethane. Propane is probed in a more narrow pressure range $([5 ; 0.5] \mathrm{hPa})$.

We treat each latitude separately, using its set of co-added spectra (a spectrum per each observed altitude) obtained from the observations (see section 2.1). The retrievals are done through an iterative method. At each iteration, a new synthetic spectrum is computed for each altitude by adding a small increment to the retrieved quantity, in order to fit the set of co-added spectra. We estimate that the algorithm converges towards a solution when the $\chi^{2}$ varies by less than $1 \%$ between two iterations. For each latitude, temperature and hydrocarbons abundances are retrieved in sequential steps. First, we retrieve the temperature. As in Guerlet et al. (2009), an altitude offset is retrieved simultaneously with the temperature profile to correct the altitudes shift mentioned in section 2. We use the tangent altitudes provided by the spacecraft navigation as a priori altitudes. The altitude offset is determined by comparing the measured and retrieved altitudes of the saturations levels of $\mathrm{CH}_{4} \nu_{4}$ band and collisions induced emissions, as the altitudes of these saturation levels are well constrained by radiative transfer theory. Then, we use the retrieved temperature to infer the ethane abundance profile. We perform eventually a 

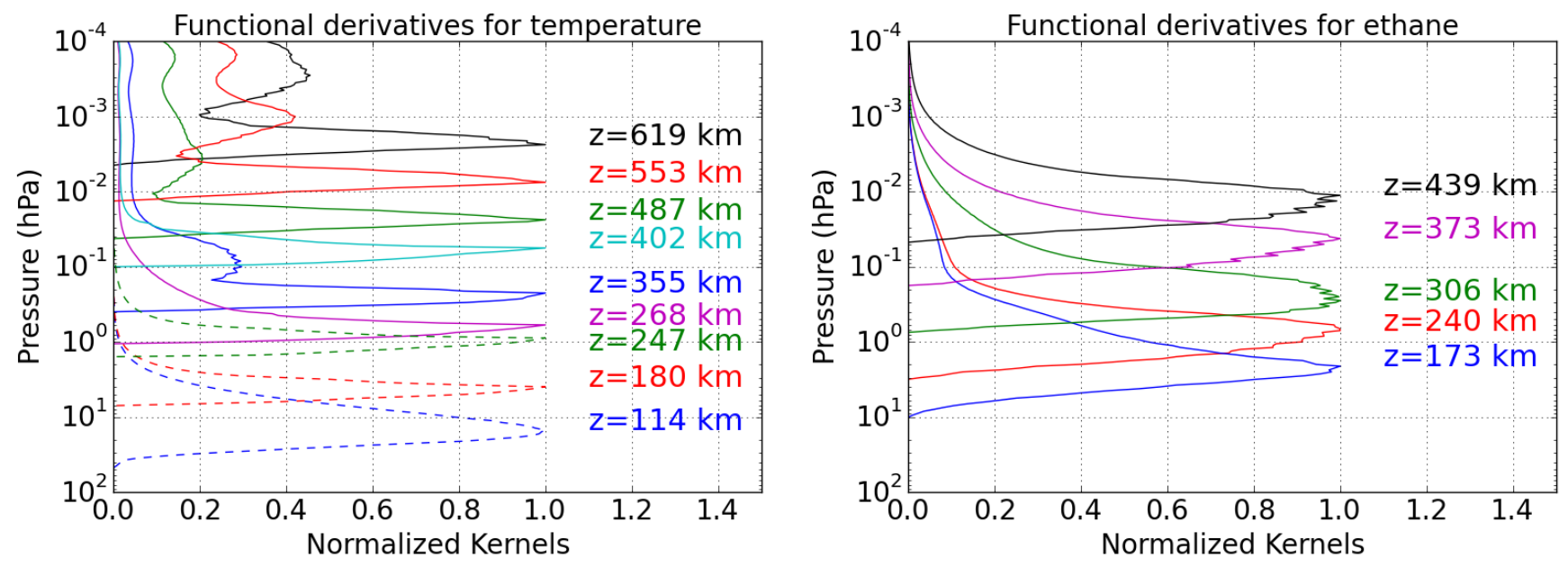

Figure 4: Functional derivatives of temperature (left) and ethane(right) at different altitudes, at $50^{\circ} \mathrm{N}$. For temperature, the functional derivatives are plotted at $1305 \mathrm{~cm}^{-1}$ (solid lines), and at $605 \mathrm{~cm}^{-1}$ (dashed lines). The functional derivatives for ethane are plotted at $815 \mathrm{~cm}^{-1}$.

third inversion to retrieve acetylene and propane volume mixing ratio, using the retrieved profiles of temperature and ethane.

The retrieval of the probed quantities from the spectra is an ill-posed problem : several distinct profiles of temperature or hydrocarbons abundances can fit a set of co-added spectra. Consequently, an a priori profile of the probed quantity is needed to initiate the inversion process and to constrain it, especially at pressure levels where the measurements are not sensitive to the probed parameters. We perform each retrievals with several a priori profiles to explore their influence on the solution profile. For temperature retrievals, we use three different a priori profiles : the vertical temperature profile measured by Lindal et al. (1985) using Voyager radio occultations, and two other profiles which are identical to Lindal et al. (1985) temperature profile below the 1-hPa pressure level and warmer above, as shown on fig. 5. For hydrocarbons abundances retrievals, we use the abundances profiles predicted by the photochemical model of Moses and Greathouse $(2005)$ and multiples $(\times 2, \times 0.5)$ of these profiles to explore sensitivity to a priori profiles. The relative weight $f$ between data and a priori profile is a parameter of our inversion algorithm. We find that the optimal values of $f$ lie between 0.3 and 3 . These values let the algorithm modify the profile following the radiance variations measured in the spectra, without being adversely affected by the measurements noise at pressure levels where the sensitivity to the probed parameters is weak. The retrieved profiles are also smoothed on a correlation length $L$ between 1 and 4 Saturn's scale height to suppress high frequency spurious oscillations (i.e occurring on vertical scales inferior to the field of view of a detector). For each latitude, we perform the retrievals with several values of $L$ and $f$ to find the best fit of the set of co-added spectra.

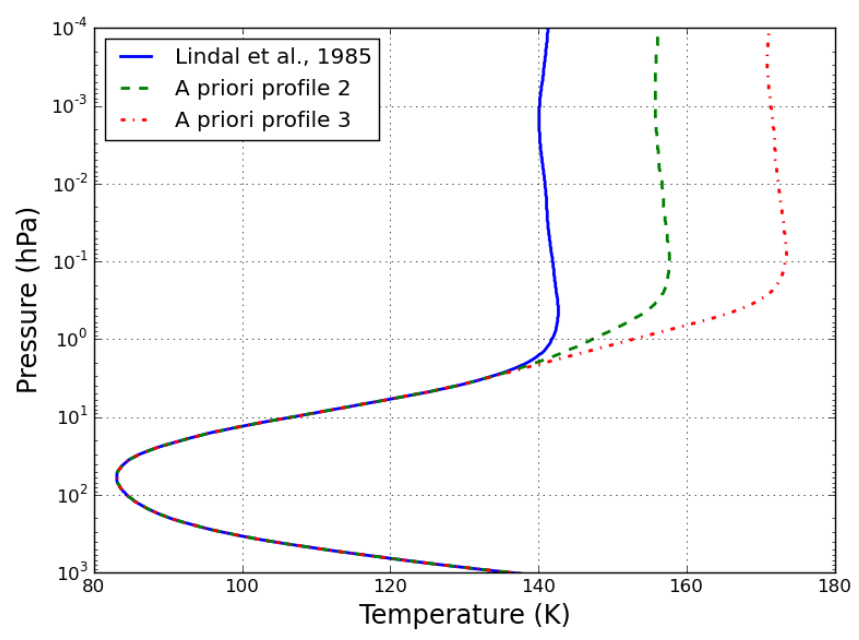

Figure 5: A priori profiles of temperature used for the temperature retrievals.

\subsubsection{Retrievals on the ALPCMAOCC001_VIMS and ALPHYAOCC001_VIMS datasets}

The temperature and hydrocarbons retrievals from ALPCMAOCC001_VIMS and ALPHYAOCC001_VIMS datasets required a specific treatment, because of the specific observation geometry affecting the acquisition (tilt of the detectors with respect to the local vertical, see section 2.2 and fig. 3). The vertical field of view $F$ of a detector is an input parameter of our radiative transfer code. For each altitude $z$, the radiative transfer code computes the corresponding synthetic spectra, by averaging the radiative contributions of 9 smaller 


\begin{tabular}{ccccccc}
\hline Pressure level & Noise and smoothing & Altitude & {$\left[\mathrm{CH}_{4}\right] /\left[\mathrm{H}_{2}\right]$} & Homopause level & {$[\mathrm{He}] /\left[\mathrm{H}_{2}\right]$} & Sum \\
\hline $10 \mathrm{hPa}$ & \pm 0.5 & ${ }_{-0.2}^{+0.4}$ & \pm 0.1 & $\leq 0.1$ & ${ }_{-1.9}^{+0.8}$ & ${ }_{-2.0}^{+1.0}$ \\
\hline $1 \mathrm{hPa}$ & \pm 0.4 & ${ }_{-0.2}^{+0.3}$ & ${ }_{-0.6}^{+0.7}$ & \pm 0.5 & ${ }_{-0.2}^{+0.4}$ & ${ }_{-0.9}^{+1.1}$ \\
\hline $0.1 \mathrm{hPa}$ & \pm 0.8 & ${ }_{-1.0}^{+0.3}$ & ${ }_{-0.6}^{+0.9}$ & ${ }_{-1.1}^{+0.8}$ & ${ }_{-0.8}^{+0.3}$ & ${ }_{-2.0}^{+1.5}$ \\
\hline $0.01 \mathrm{hPa}$ & \pm 0.7 & ${ }_{-0.7}^{+0.4}$ & ${ }_{-0.9}^{+1.2}$ & \pm 0.6 & \pm 0.2 & ${ }_{-1.5}^{+1.6}$ \\
\hline
\end{tabular}

Table 2: Error estimation on the temperature in Kelvin at different pressure levels, for the different sources of error. In the last column, we computed the quadratic sum $\left(\sqrt{\sum_{i}{\sigma_{i}}^{2}}\right)$ of all the errors $\left(\sigma_{i}\right)$.

\begin{tabular}{cccc}
\hline Pressure levels $(\mathrm{hPa})$ & Ethane & Acetylene & Propane \\
\hline 1 & $\begin{array}{l}+19 \% \\
-15 \%\end{array}$ & $\begin{array}{l}+18 \% \\
-16 \%\end{array}$ & $+22 \%$ \\
\hline 0.1 & $+25 \%$ & $+27 \%$ & \\
\hline \multirow{2}{*}{0.01} & $-22 \%$ & $-22 \%$ & \\
\hline
\end{tabular}

Table 3: Error estimation on the hydrocarbons abundances at different pressure levels. We present here the quadratic sum of the errors $\left(\sqrt{\sum_{i} \sigma_{i}^{2}}\right)$ affecting the hydrocarbons retrievals.

atmospheric layers cut alongside to the local vertical, which height is $F / 9$, and which altitudes are between $z-F / 2$ and $z+F / 2$. When the detectors arrays are parallel to the local vertical ("regular" limb geometry), each layer has the same weight. With the geometry of the ALPCMAOCC001_VIMS and ALPHYAOCC001_VIMS datasets, if the part of the atmosphere probed by a single detector is cut alongside to the local vertical, in the same way as in the radiative transfer code, the atmospheric layers obtained will have different sizes and different radiative contributions. Hence, the method of calculation used in the radiative transfer code is inaccurate for the geometry of these two datasets, which can induce a bias in the computation of the synthetic spectra and in the retrievals of temperature and hydrocarbons abundances. To overcome this issue, we choose to study the following extreme cases : we retrieve the temperature profiles, using the measured field of view, the theoretical field of view (knowing the angular field of view and the distance between the spacecraft and the planet), and the maximal field of view (see fig. 3) as values of $F$ for the radiative transfer code. For each latitude, we keep the value of $F$ giving the best fit of the set of co-added spectra, then we use it for the hydrocarbons abundances retrievals.

In the datasets at $42^{\circ} \mathrm{S}, 47^{\circ} \mathrm{S}$ and $50^{\circ} \mathrm{S}$, the low signal to noise ratio of the spectra acquired at the $0.01-\mathrm{hPa}$ pressure level (and above) prevents to measure precisely the temperature at this pressure level. For each of these latitudes, we use the temperature retrievals performed with the three a priori profiles (presented in fig. 5), in order to find an upper limit of the temperature at $0.01 \mathrm{hPa}$, i.e the maximal temperature at this pressure level with which the radiative transfer code can fit the corresponding co-added spectra. As the temperature can not be retrieved accurately at $0.01 \mathrm{hPa}$, we do not retrieve hydrocarbons abundances at this pressure level.

We do not perform retrievals on the dataset at $55^{\circ} \mathrm{S}$, because of the low signal to noise ratio (due to a shorter acquisition time than in the other datasets or to lower temperatures) in the co-added spectra, preventing us from detecting clearly the spectral band of $\mathrm{CH}_{4}$ (needed to retrieve the temperature).

\subsubsection{Error analysis}

We evaluate below the different sources of error affecting our results. They are summed up in table 2 for temperature and table 3 for hydrocarbons volume mixing ratios. Our retrieval algorithm estimates directly the error induced by data noise and smoothing of the retrieved profiles by the algorithm. An additional series of retrievals are performed to estimate the errors induced by :

- the determination of the tangent altitudes of the spectra : we estimate that the error on the retrieved tangent altitudes (see section 2) is $\pm 7 \mathrm{~km}$, as it is the minimal shift needed to increase significantly the $\chi^{2}$ in the altitude retrievals. We retrieve temperature and hydrocarbons abundances profiles using the altitudes previously retrieved, shifted by $\pm 7 \mathrm{~km}$.

- the error on the abundance of $\mathrm{CH}_{4}( \pm 20 \%$, Flasar et al. (2005)). It affects only temperature retrievals. 
- the uncertainty on the ratio $[\mathrm{He}] /\left[\mathrm{H}_{2}\right]$ which is comprised between 0.08 and 0.16 (Conrath and Gautier, 2000; Flasar et al., 2008). It affects only temperature retrievals. In limb geometry, these errors are quite weak (up to $1.9 \mathrm{~K}$ ) compared to nadir geometry (up to $4 \mathrm{~K}$ in Fletcher et al. (2007)) because limb geometry is more sensitive to the vertical temperature variations than nadir geometry. Moreover, errors related to the uncertainty on $[\mathrm{He}] /\left[\mathrm{H}_{2}\right]$ affects especially temperature retrievals at high pressures (lower than $10 \mathrm{hPa}$ ), as temperature is mainly retrieved using the $\mathrm{H}_{2}$ collisions induced emission. The contribution of the $\mathrm{CH}_{4} \nu_{4}$ band emission to the temperature retrievals becomes more and more important with decreasing pressure and lowers the influence of this error source.

- the uncertainty on the altitude of $\mathrm{CH}_{4}$ homopause : Moses and Vervack (2006) show that the homopause pressure level can vary with altitude and time. We perform temperature retrievals, setting a $\mathrm{CH}_{4}$ profile where the homopause level is shifted by a pressure decade downward.

- the propagation of errors affecting temperature on the hydrocarbon abundances retrievals. We retrieve the hydrocarbons abundances, setting the temperature profile to its upper or lower limit, determined by the analysis of the errors sources listed above.

Most of error estimations listed in tables 2 and 3 are not symmetric, because the parameters from which they depend are taken into account in the derivations of absorption and emission of atmospheric gases by the radiative transfer code, which are not linear functions of temperatures and hydrocarbons abundances.

\section{Results}

\subsection{Temperature}

Figure 6 shows two examples of retrieved vertical temperature profiles at $30^{\circ} \mathrm{N}\left(L_{S}=12^{\circ}\right)$ and $47^{\circ} \mathrm{S}$ $\left(L_{S}=31^{\circ}\right)$ and their comparison with the previous measurements from Guerlet et al. (2009) (at $L_{S}=312^{\circ}$ and $L_{S}=315^{\circ}$ respectively). They are representative of the thermal evolution of the stratosphere in each hemisphere. In the northern hemisphere, from winter to spring, the temperature increases within the whole probed pressure range. The maximum increase of temperature is centred around $1 \mathrm{hPa}$ and reaches $7 \pm_{0.9}^{1.1} \mathrm{~K}$. The spring warming amplitude decreases with altitude to eventually vanish (within error bars) at $0.01 \mathrm{hPa}$. In other words, the seasonal contrast of temperature varies strongly with altitude in the northern hemisphere. The picture is radically different in the southern hemisphere. The temperature remains constant from summer to autumn from $10 \mathrm{hPa}$ to $0.1 \mathrm{hPa}$. Then, at higher altitudes, the temperature decreases strongly between the two seasons. For instance, at $47^{\circ} \mathrm{S}$, the thermal contrast from $L_{S}=315^{\circ}$ to $L_{S}=31^{\circ}$ is at least $13 \pm_{1.5}^{1.6} \mathrm{~K}$ at $0.01 \mathrm{hPa}$ (the determination of an upper limit for temperature at $0.01 \mathrm{hPa}$ in this dataset is detailed in 2.3.2). The asymmetry of the evolution of the stratospheric thermal structure between the two hemispheres is puzzling, since one would expect radiative timescale to vary little with latitude, given the small temperature and composition gradients.

Figure 7 presents how the temperature meridional gradient evolves at several pressure levels. The evolution of the equatorial belt $\left(20^{\circ} \mathrm{S}\right.$ to $\left.20^{\circ} \mathrm{N}\right)$ is already presented by Guerlet et al. (2011) and reflects the downward propagation of Saturn equatorial oscillation in the stratosphere (Fouchet et al., 2008; Orton et al., 2008), a temperature oscillation, probably driven by upward propagating waves, affecting the latitudes between $20^{\circ} \mathrm{S}$ and $20^{\circ} \mathrm{N}$. We focus here on the seasonal and regional trends of the two hemispheres (from $25^{\circ} \mathrm{N}$ to $79^{\circ} \mathrm{N}$ and from $25^{\circ} \mathrm{S}$ to $70^{\circ} \mathrm{S}$ ).

\section{Northern hemisphere $\left(25^{\circ} \mathrm{N}\right.$ to $\left.79^{\circ} \mathrm{N}\right)$}

- At $10 \mathrm{hPa}$, in northern spring, temperature decreases sharply by $18 \pm_{2.0}^{1.0} \mathrm{~K}$ from $25^{\circ} \mathrm{N}$ to the north pole. The seasonal evolution of temperature is globally negligible (within error bars).

- At $1 \mathrm{hPa}$, in spring, similarly to $10 \mathrm{hPa}$, there is a strong meridional thermal gradient : temperature decreases by $19 \pm_{0.9}^{1.1} \mathrm{~K}$ from $30^{\circ} \mathrm{N}$ to $79^{\circ} \mathrm{N}$. The temperature increases strongly from winter to spring. The maximum increase of temperature is located at $40^{\circ} \mathrm{N}$, where it reaches $11 \pm_{0.9}^{1.1} \mathrm{~K}$.

- At $0.1 \mathrm{hPa}$, the meridional temperature gradient is weaker than at higher pressures : the temperature decreases by $12 \pm_{2.0}^{1.5} \mathrm{~K}$ from $25^{\circ} \mathrm{N}$ to $79^{\circ} \mathrm{N}$. The seasonal thermal contrast is also globally weaker than at $1 \mathrm{hPa}$. However, at $70^{\circ} \mathrm{N}$, the difference between winter and spring temperatures is higher than at $1 \mathrm{hPa}\left(12 \pm_{2.0}^{1.5} \mathrm{~K}\right.$ at $0.1 \mathrm{hPa}$ versus $5 \pm_{0.9}^{1.1} \mathrm{~K}$ at 1 $\mathrm{hPa})$.

- At $0.01 \mathrm{hPa}$, contrary to the other pressures levels, the temperature does not show a regular decrease from low to high latitudes. From $25^{\circ} \mathrm{N}$ to $50^{\circ} \mathrm{N}$ the temperature is uniform, then there is a strong decrease of $11 \pm_{1.5}^{1.6} \mathrm{~K}$ towards $60^{\circ} \mathrm{N}$ and $70^{\circ} \mathrm{N}$. The temperature rises again towards the pole by $6 \pm_{1.5}^{1.6} \mathrm{~K}$. From $25^{\circ} \mathrm{N}$ to $45^{\circ} \mathrm{N}$, the temperature difference between the two seasons is negligible within error bars. Unlike the previous pressure levels, we cannot infer the seasonal evolution of temperature at $70^{\circ} \mathrm{N}$ : the low signal to noise ratio of the spectra acquired at this latitude, at $0.01 \mathrm{hPa}$ in winter (December 2007), 

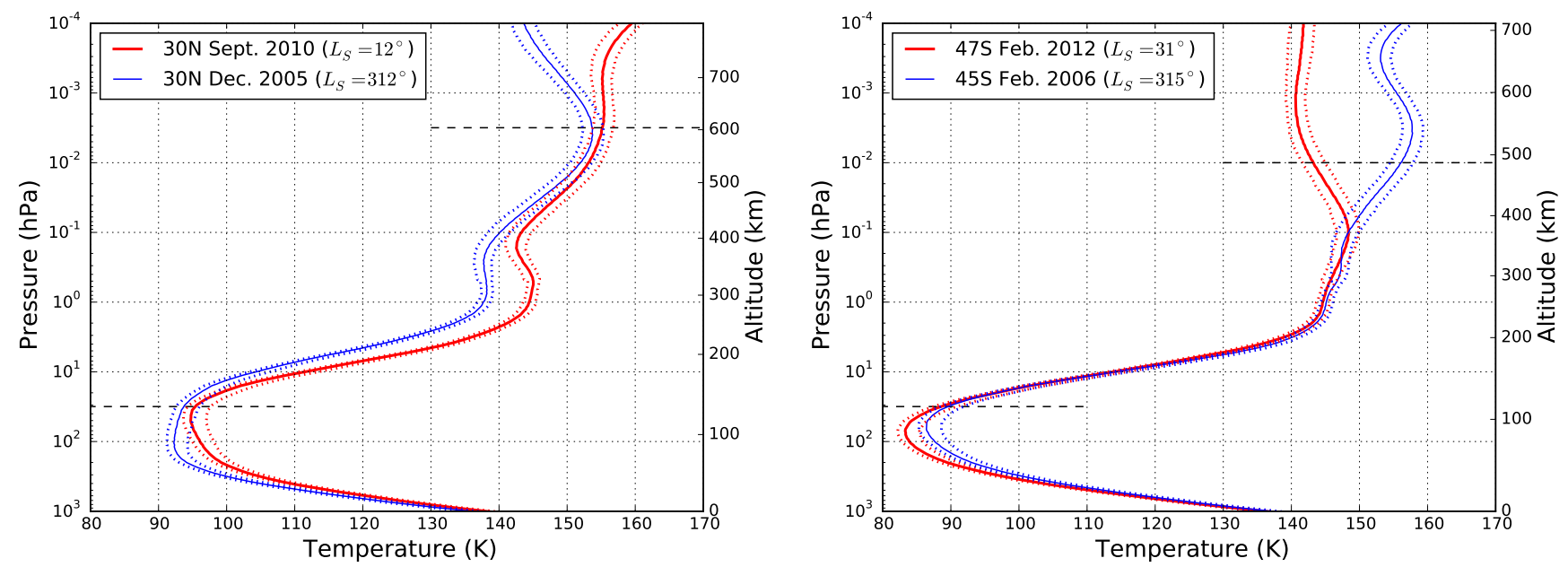

Figure 6: Vertical retrieved temperature profiles at $30^{\circ} \mathrm{N}$ and $47^{\circ} \mathrm{S}$. Red thick solid lines represent the temperature inferred from the datasets presented in this paper, whereas blue thin solid lines represent the previous results presented in Guerlet et al. (2009). Dotted lines stand for the error envelopes of each profile. Dashed horizontal lines represent the sensitivity limits of our data in altitude. Beyond these lines, differences between the profiles are mainly due to the use of different parameters (e.g. smoothing factors, a priori profiles) in the retrievals.

prevents Guerlet et al. (2009) from measuring the temperature.

Hence, in the springtime northern hemisphere, the meridional gradient of temperature is higher in the lower stratosphere (from $10 \mathrm{hPa}$ to $1 \mathrm{hPa}$ ) than in the upper stratosphere (above the 0.1-hPa pressure level). Our observations performed in spring even show that the temperature is approximately constant from low to mid-latitudes at $0.01 \mathrm{hPa}$. CIRS limb measurements at $50^{\circ} \mathrm{N}, 60^{\circ} \mathrm{N}$, and $79^{\circ} \mathrm{N}$, presented for the first time in this study, fit well in these meridional trends of temperature. At all northern latitudes, the seasonal evolution of temperature varies strongly with pressure. The maximum seasonal thermal contrast is located at $1 \mathrm{hPa}$ and decreases toward higher and lower pressure levels.

\section{Southern hemisphere $\left(25^{\circ} \mathrm{S}\right.$ to $\left.70^{\circ} \mathrm{S}\right)$}

- At $10 \mathrm{hPa}$, in southern autumn, the meridional temperature gradient is weak. The temperature decreases by $4 \pm_{2.0}^{1.0} \mathrm{~K}$ from $35^{\circ} \mathrm{S}$ to $50^{\circ} \mathrm{S}$, but increases by $2 \pm_{2.0}^{1.0} \mathrm{~K}$ towards $70^{\circ} \mathrm{S}$. At mid-latitudes, the temperature remains constant from summer to autumn within error bars whereas at $70^{\circ} \mathrm{S}$, temperature decreases by $12 \pm_{2.0}^{1.0} \mathrm{~K}$ between the two seasons.

- At $1 \mathrm{hPa}$, in autumn, the temperature is approximately constant between $42^{\circ} \mathrm{S}$ and $47^{\circ} \mathrm{S}$, whereas the atmosphere exhibits a surprising cooling of $8 \pm_{0.9}^{1.1} \mathrm{~K}$ from $47^{\circ} \mathrm{S}$ to $50^{\circ} \mathrm{S}$. Like at $10 \mathrm{hPa}$, the seasonal contrast of temperature is negligible at mid-latitude and is $12 \pm_{0.9}^{1.1} \mathrm{~K}$ at $70^{\circ} \mathrm{S}$.

- At $0.1 \mathrm{hPa}$, in autumn, the temperature meridional gradient is similar to that measured at $1 \mathrm{hPa}$. The cooling between $47^{\circ} \mathrm{S}$ and $50^{\circ} \mathrm{S}$ is stronger at $0.1 \mathrm{hPa}$ than at $1 \mathrm{hPa}$. The meridional thermal gradient from $35^{\circ} \mathrm{S}$ to $70^{\circ} \mathrm{S}$ is $13 \pm_{2.0}^{1.5} \mathrm{~K}$. The seasonal evolution of the temperature is the same as it is at $10 \mathrm{hPa}$ and $1 \mathrm{hPa}$.

- At $0.01 \mathrm{hPa}$, we measure a temperature contrast of $15 \pm{ }_{1.5}^{1.6} \mathrm{~K}$ between $35^{\circ} \mathrm{S}$ and $70^{\circ} \mathrm{S}$. However, we have little information about the temperature meridional gradients, as we retrieve only upper limits for temperatures from $42^{\circ} \mathrm{S}$ to $50^{\circ} \mathrm{S}$. In contrast with the situation at higher pressures, the temperature decreases strongly from summer to autumn at midlatitudes (decrease of at least $17 \mathrm{~K}$ at $42^{\circ} \mathrm{S}$ ). The seasonal cooling at $70^{\circ} \mathrm{S}$ is $12 \pm_{1.5}^{1.6} \mathrm{~K}$, similarly to higher pressure levels.

In the southern hemisphere, temperature decreases from mid-latitudes to polar regions, at all pressure levels during autumn. At this season, in the 1-0.1 hPa pressure range, the temperature retrieved at $50^{\circ} \mathrm{S}$ is much cooler than the retrieved temperature of the surrounding latitudes. Such a sharp cooling is puzzling and will be discussed in section 4 . The meridional gradient of temperature from low to high latitudes is less steep in the southern hemisphere than in the northern hemisphere. In the southern hemisphere, from $10 \mathrm{hPa}$ to $0.1 \mathrm{hPa}$, the seasonal temperature contrast is globally negligible (within error bars). Then at $0.01 \mathrm{hPa}$, the atmosphere cools strongly from summer to autumn. This global seasonal trend for temperature does not apply at $70^{\circ} \mathrm{S}$, where the atmosphere cools by $12 \mathrm{~K}$ from summer to autumn, at all the probed pressure levels. The steep temperature increase observed in southern summer between southern mid-latitudes and $70^{\circ} \mathrm{S}$ at $10 \mathrm{hPa}$ and $1 \mathrm{hPa}\left(\right.$ e.g $13 \pm_{2.0}^{1.0} \mathrm{~K}$ at $\left.10 \mathrm{hPa}\right)$, dis- 

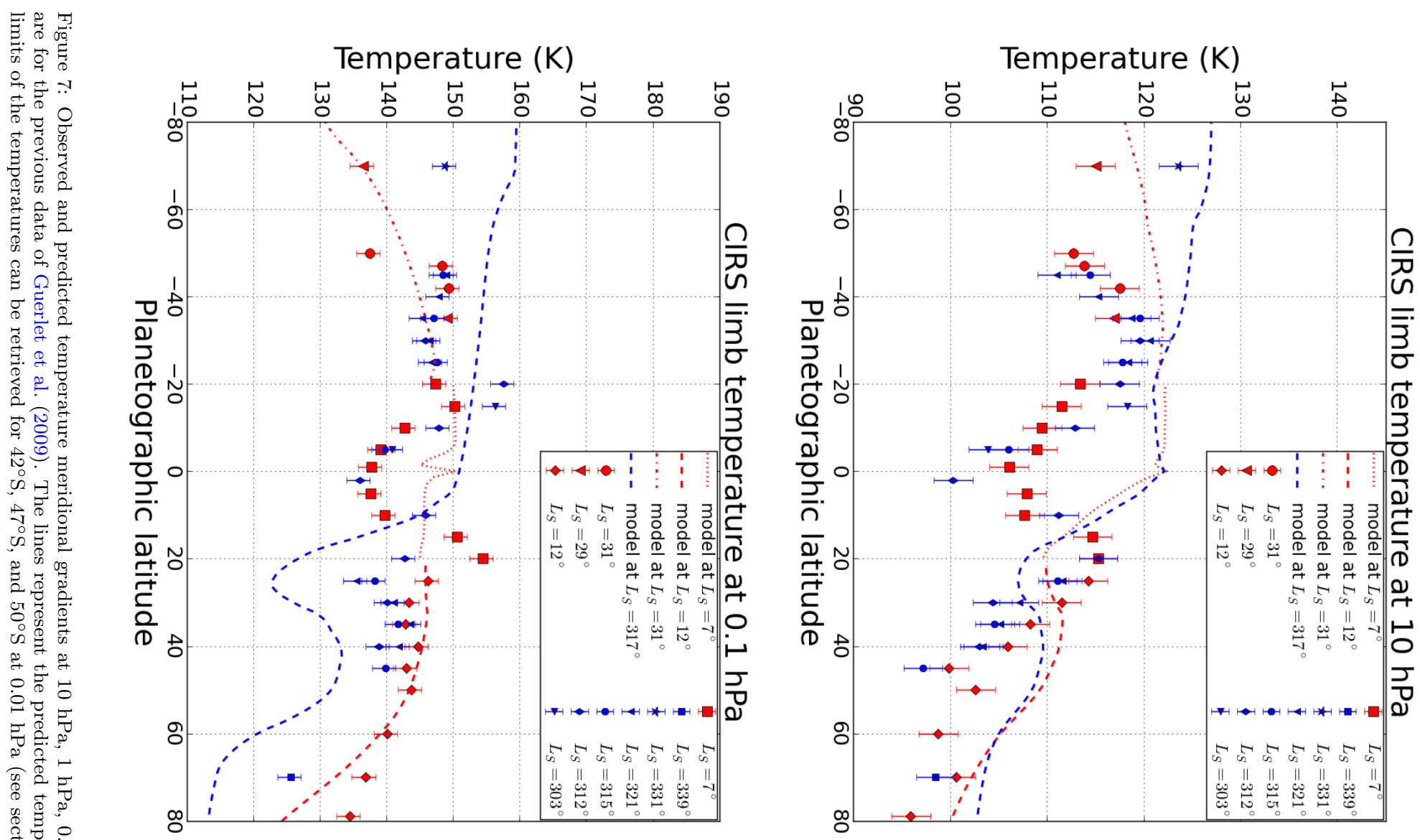

N

نे

孛追

节守

Temperature (K)

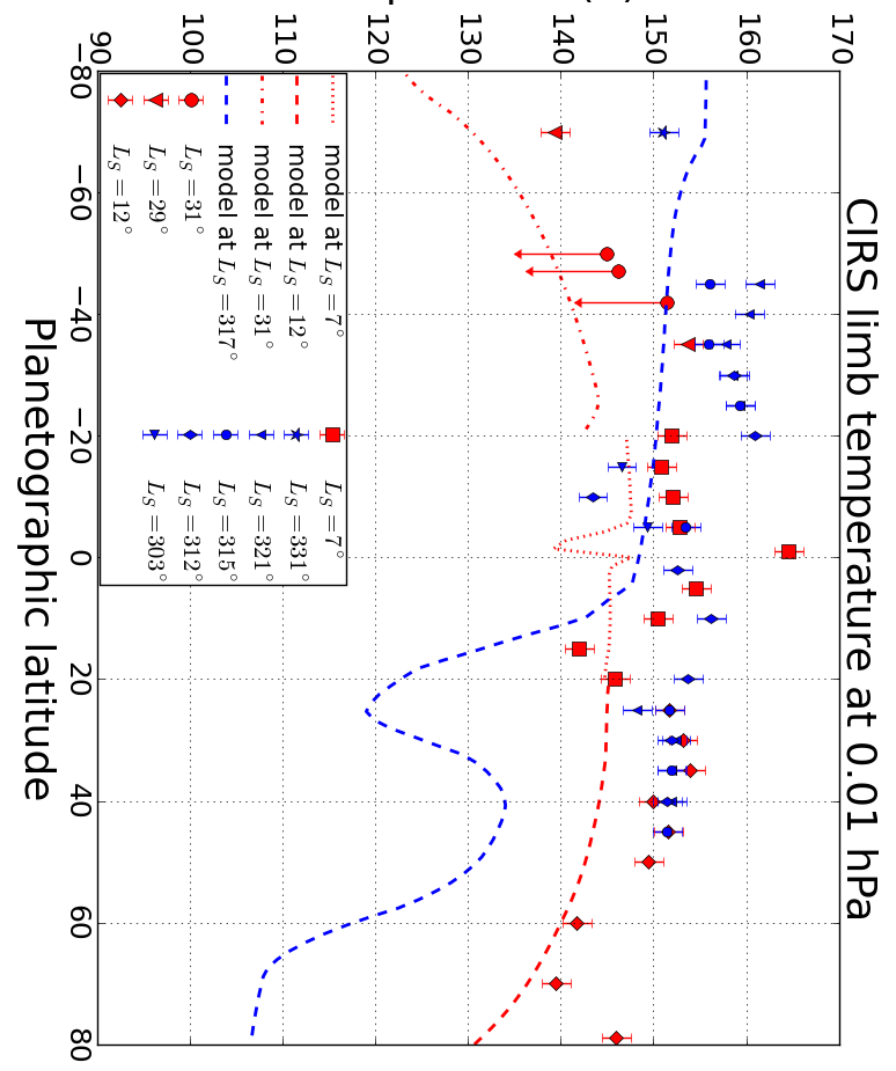

Temperature (K)

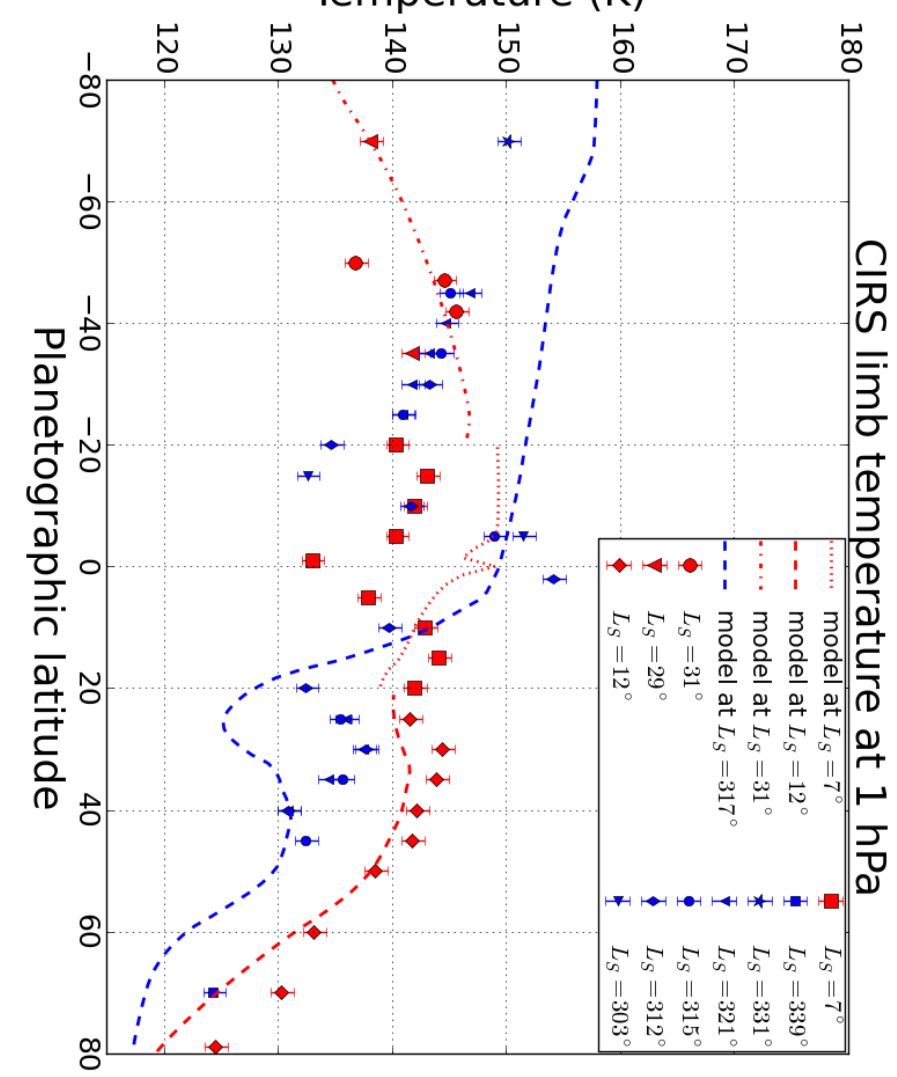


appears in autumn to be replaced by nearly homogeneous temperatures between mid and high southern latitudes.

\subsection{Hydrocarbons}

Figure 8 shows two examples of retrieved abundances profiles of ethane and acetylene at $40^{\circ} \mathrm{N}\left(L_{S}=12^{\circ}\right)$ and $42^{\circ} \mathrm{S}\left(L_{S}=31^{\circ}\right)$ and their comparison with the previous measurements from Guerlet et al. (2009) (at $L_{S}=321^{\circ}$ ). The retrieved propane abundance profiles for the same latitudes and observations times are also shown in fig. 8. They are representative of the evolution of the abundances of these hydrocarbons in each hemisphere. At $40^{\circ} \mathrm{N}$, the abundances of ethane and acetylene remain approximately constant from winter to spring. At $42^{\circ} \mathrm{S}$, below the 1-hPa pressure level, the evolution of ethane and acetylene abundances is negligible. However, at lower pressures, the abundances of these hydrocarbons increase strongly. For instance, the volume mixing ratios of $\mathrm{C}_{2} \mathrm{H}_{2}$ and $\mathrm{C}_{2} \mathrm{H}_{6}$ are doubled (at $\pm_{22 \%}^{25 \%}$ for $\mathrm{C}_{2} \mathrm{H}_{6}$ and at $\pm_{22 \%}^{27 \%}$ for $\mathrm{C}_{2} \mathrm{H}_{2}$ ) at $0.1 \mathrm{hPa}$ from southern summer to autumn. In both hemispheres, the vertical profile of propane show few seasonal variations.

Figure 9 shows the meridional distribution of hydrocarbons and its seasonal evolution. We examine the seasonal variations at all latitudes.

- At $1 \mathrm{hPa}$, the most striking result is that ethane, acetylene and propane abundances hardly exhibit any seasonal evolution. Their meridional distributions is remarkably constant (at $\pm_{15 \%}^{19 \%}$ for $\mathrm{C}_{2} \mathrm{H}_{6}$, $\pm_{16 \%}^{18 \%}$ for $\mathrm{C}_{2} \mathrm{H}_{2}$ and $\pm_{24 \%}^{22 \%}$ for $\left.\mathrm{C}_{3} \mathrm{H}_{8}\right)$ from northern winter to spring. The meridional gradients of abundances of these two hydrocarbons are different, and that for both seasons. Acetylene volume mixing ratio decreases from equator to poles. Conversely, ethane and propane are homogeneously distributed in latitude. Newly probed latitudes (at $50^{\circ} \mathrm{S}, 50^{\circ} \mathrm{N}, 60^{\circ} \mathrm{N}$, and $79^{\circ} \mathrm{N}$ ) in northern spring seem to show marginal hints of increasing abundances toward the south pole for propane, and towards both poles for ethane.

- At $0.1 \mathrm{hPa}$, in northern spring, the meridional distributions of acetylene and ethane follow identical trends : the maxima of concentrations are reached at the equator, and decrease towards higher latitudes (except for southern mid-latitudes). The seasonal variations of acetylene and ethane abundances are globally negligible. However, in the southern midlatitudes, the volume mixing ratios of ethane and acetylene increase significantly between the two seasons (by $\sim 107 \pm_{22}^{25} \%$ for ethane and $130 \pm_{22}^{27} \%$ for acetylene).

- At $0.01 \mathrm{hPa}$, the meridional distribution of hydrocarbons in spring is asymmetric : in the southern hemisphere, the abundances of ethane and acetylene are lower than in the northern hemisphere. Volume mixing ratios of $\mathrm{C}_{2} \mathrm{H}_{6}$ and $\mathrm{C}_{2} \mathrm{H}_{2}$ are maximum around the equator and decreases towards higher latitudes. From $20^{\circ} \mathrm{N}$ to $79^{\circ} \mathrm{N}$ and from $20^{\circ} \mathrm{S}$ to $35^{\circ} \mathrm{S}$, ethane and acetylene volume mixing ratios are approximately constant within error bars $\left( \pm_{19 \%}^{23 \%}\right.$ for $\mathrm{C}_{2} \mathrm{H}_{6}, \pm_{35 \%}^{40 \%}$ for $\mathrm{C}_{2} \mathrm{H}_{2}$ ). From $20^{\circ} \mathrm{N}$ to $30^{\circ} \mathrm{N}$, wintertime measurements show a local maximum of both hydrocarbons. In spring, this local maximum has disappeared. At the other latitudes, the abundances of both hydrocarbons remain globally constant from northern winter to spring.

At $1 \mathrm{hPa}$, hydrocarbons abundances are constant (at $\pm_{15 \%}^{19 \%}$ for $\mathrm{C}_{2} \mathrm{H}_{6}, \pm_{16 \%}^{18 \%}$ for $\mathrm{C}_{2} \mathrm{H}_{2}$ and $\pm_{24 \%}^{22 \%}$ for $\mathrm{C}_{3} \mathrm{H}_{8}$ ) from winter to spring. At both seasons, the meridional distribution of $\mathrm{C}_{2} \mathrm{H}_{2}$ differs from the distribution of $\mathrm{C}_{2} \mathrm{H}_{6}$ and $\mathrm{C}_{3} \mathrm{H}_{8}$. At lower pressures, the meridional distribution of $\mathrm{C}_{2} \mathrm{H}_{2}$ and $\mathrm{C}_{2} \mathrm{H}_{6}$, and their seasonal variations are similar.

\subsection{Comparison with previous results}

Fletcher et al. (2010) and Sinclair et al. (2013) studied the seasonal evolution of temperature (from 2004 to 2009) and hydrocarbon abundances (from 2005 to 2010), using Cassini/CIRS nadir observations. In fig. 10, we compare these results to ours and to those of Guerlet et al. (2009), obtained with Cassini/CIRS limb observations.

Our limb measurements of temperature are in overall good agreement with the nadir results of Fletcher et al. (2010). The meridional distributions of temperature are similar for both seasons. We notice some disagreements around the equator. Fletcher et al. (2010) and Sinclair et al. (2013) showed that these differences can be accounted for by the different sensitivity to the vertical structure of the equatorial oscillation between limb and nadir geometry. In the southern hemisphere, nadir measurements show a cooling from southern summer to autumn. Conversely, at $42^{\circ} \mathrm{S}$ and $47^{\circ} \mathrm{S}$, we measure higher temperatures than Fletcher et al. (2010), and no seasonal temperature evolution from southern summer to autumn. However, the limb measurements in autumn at $70^{\circ} \mathrm{S}, 50^{\circ} \mathrm{S}$ and $35^{\circ} \mathrm{S}$ are close to the nadir results. Hence, mid-southern-latitudes may be prone to a local phenomenon such as atmospheric waves, left unresolved by the limb observations of February 2012. These would mean that the limb results for these latitudes might not be fully representative of the seasonal evolution. Guerlet et al. (2009) also find hints for wave activity, as temperature measurements at $5^{\circ} \mathrm{S}$ and $15^{\circ} \mathrm{S}$, vary by 7-15 $\mathrm{K}$ at $0.01 \mathrm{hPa}$ between observations separated by one year.

For hydrocarbons abundances, limb results show some disagreements with nadir measurements. Limb measurements of ethane abundance performed during northern winter are similar to nadir measurements at the same 

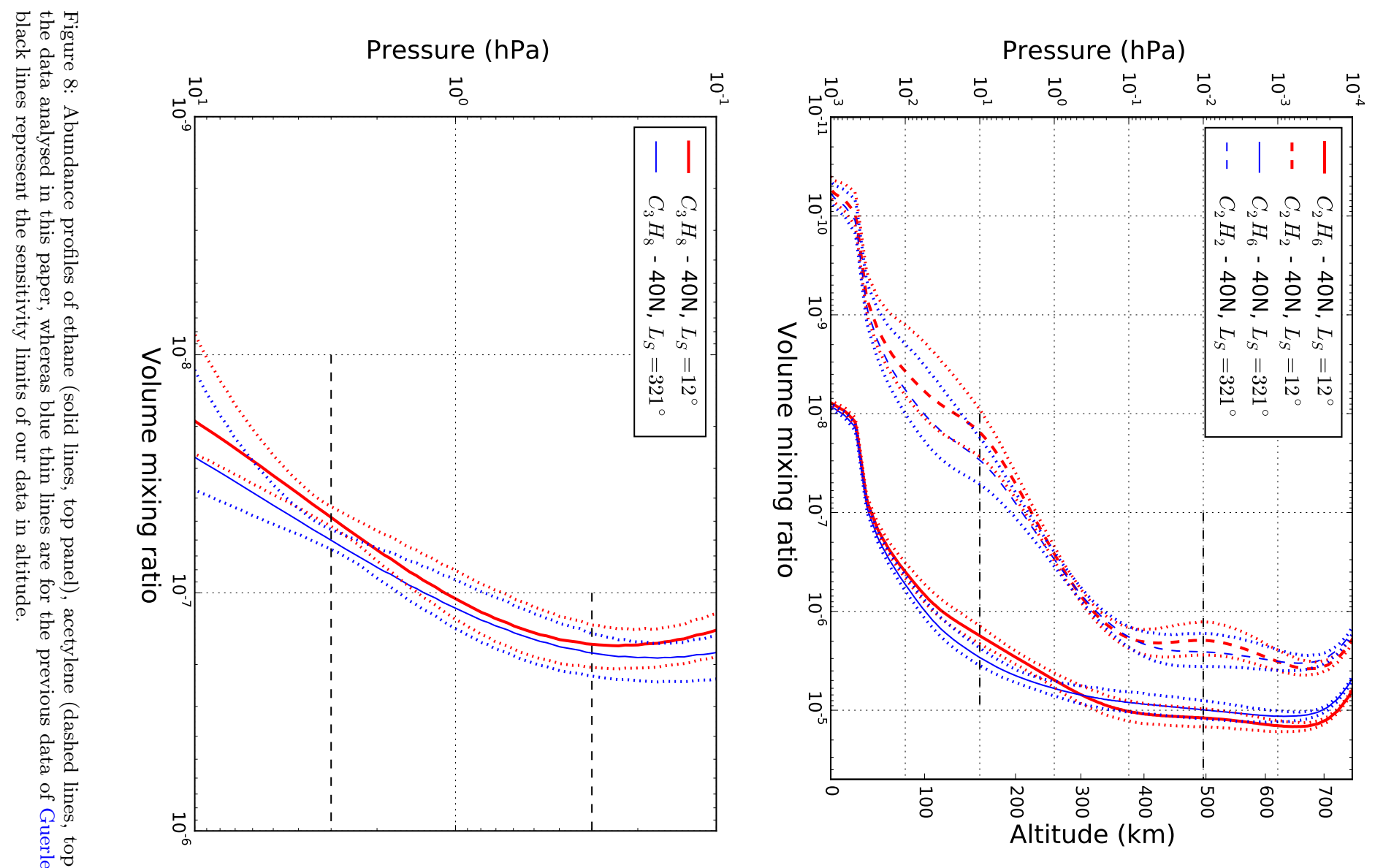

कृ

Pressure (hPa)

Pressure (hPa)

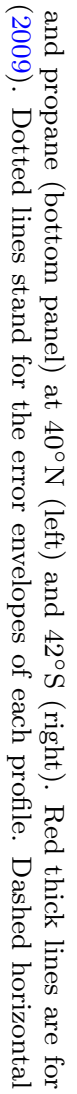

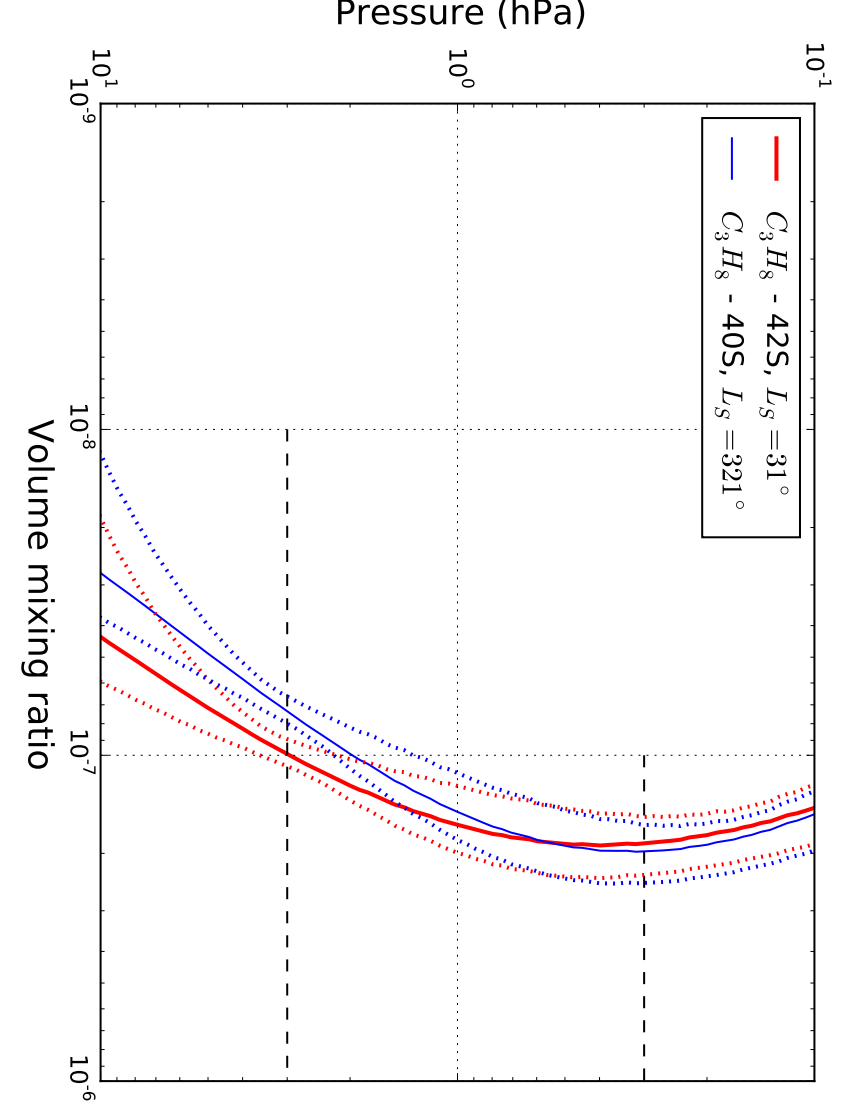

$\stackrel{\bullet}{\circ}$

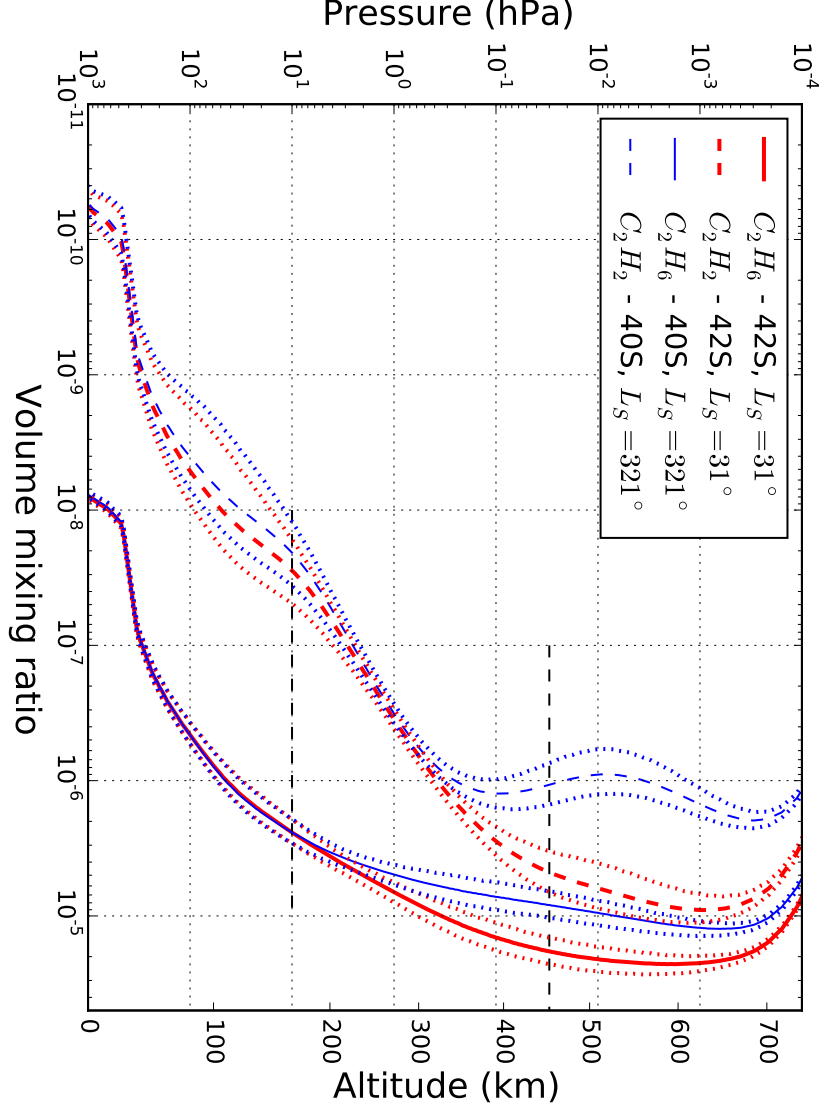



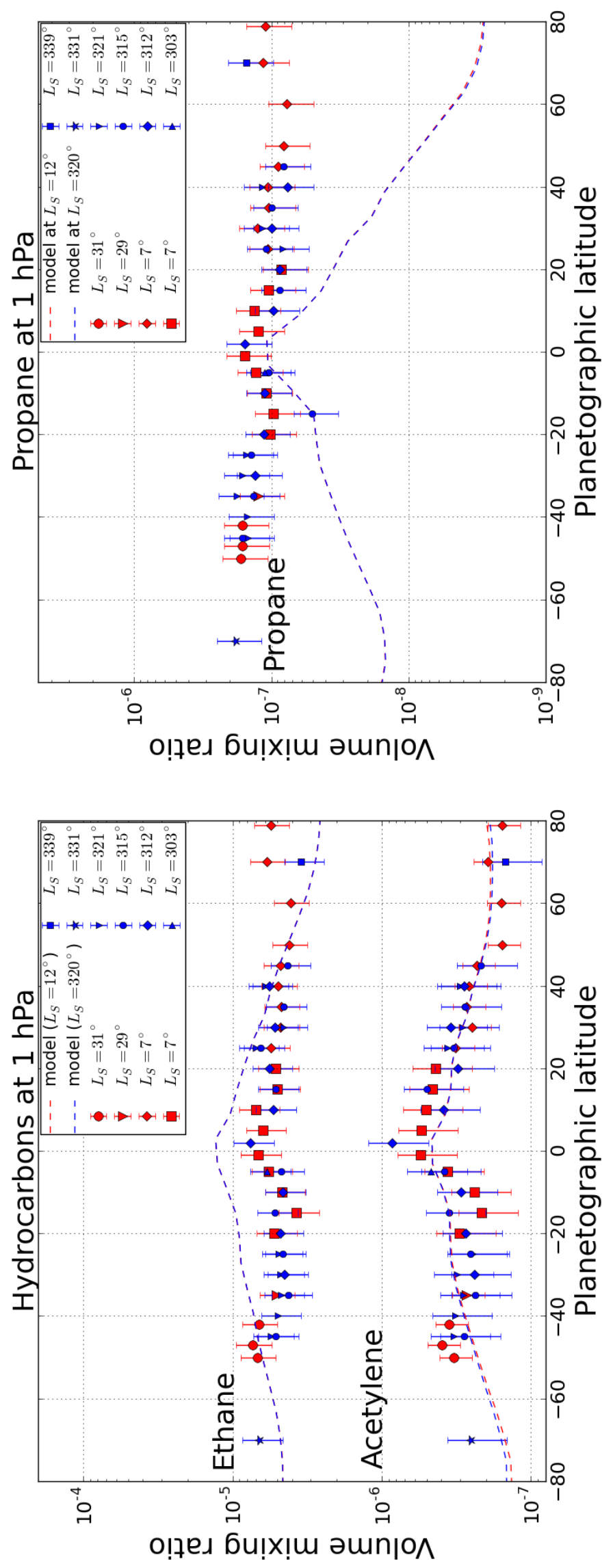
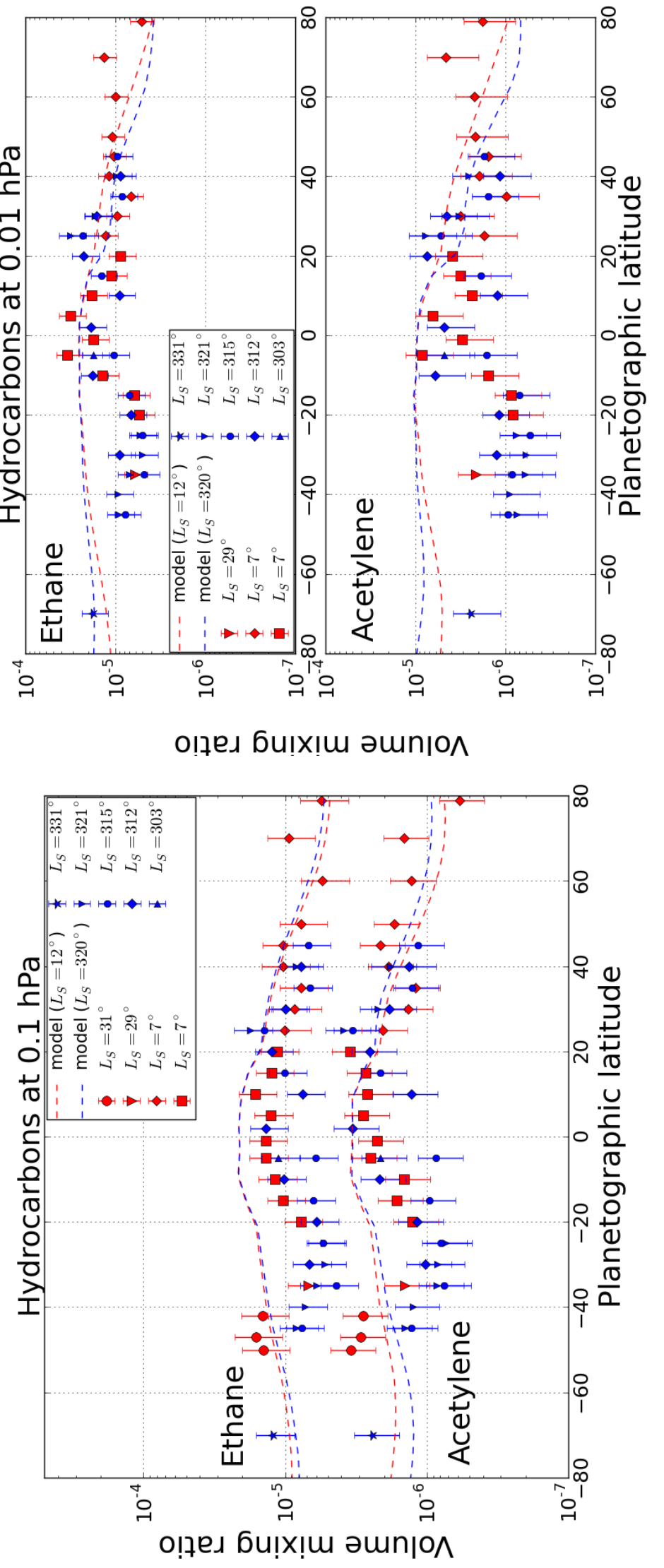

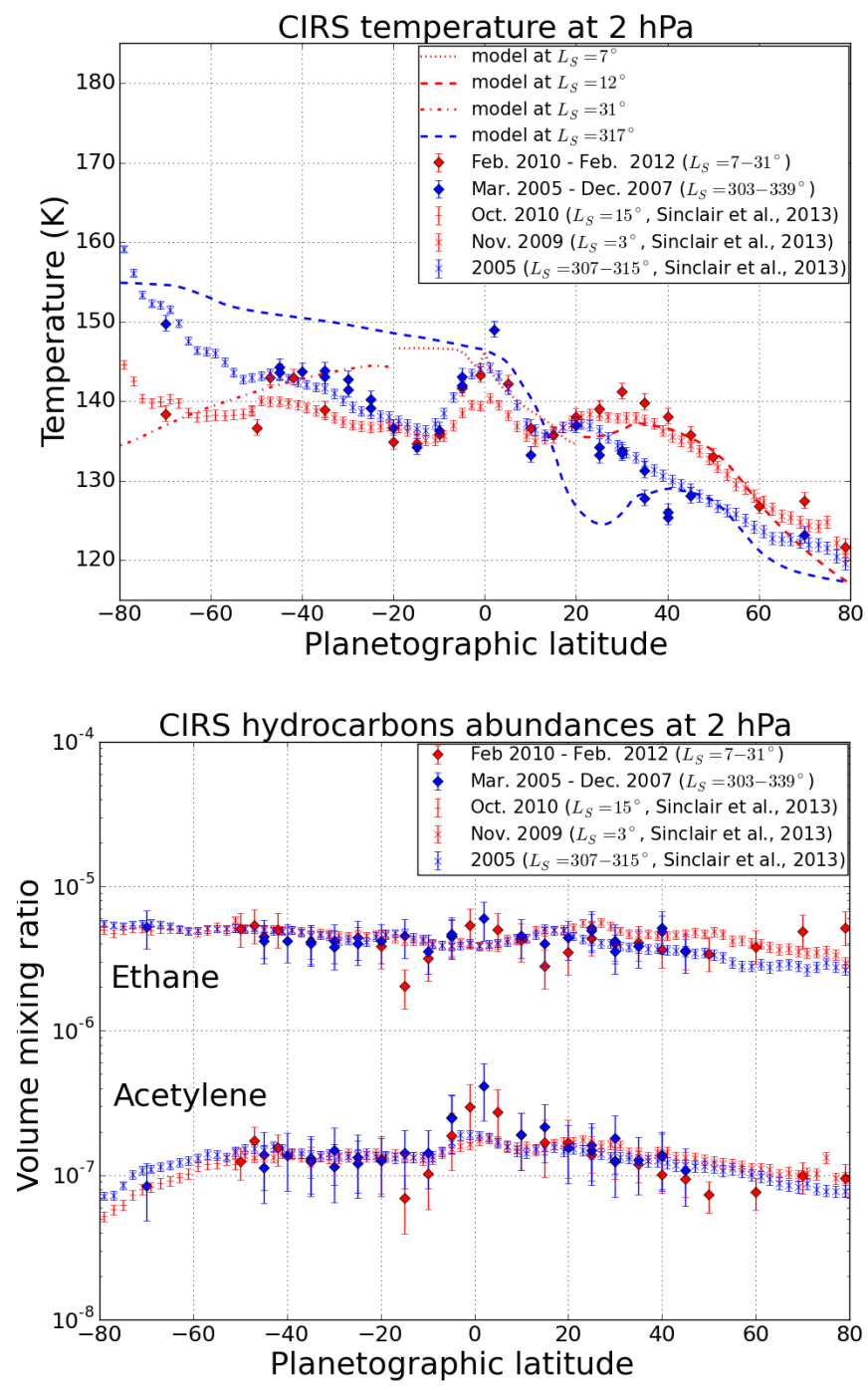

Figure 10: Comparison of our limb measurements (diamonds) to the nadir results (crosses and dashes) obtained by Fletcher et al. (2010) and Sinclair et al. (2013) at $2 \mathrm{hPa}$. The top panel shows the temperature and the bottom panel presents the $\mathrm{C}_{2} \mathrm{H}_{6}$ and $\mathrm{C}_{2} \mathrm{H}_{2}$ abundances. Red points stand for measurements performed during northern spring, and blue points for measurements performed during northern winter. The lines represent the predicted temperatures by the radiative-convective model of Guerlet et al. (2014).

season. By contrast, limb and nadir results for northern spring are different. The same differences between limb and nadir measurements seems to exist for acetylene but the larger error bars make the comparison between the two studies more difficult. Sinclair et al. (2013) noticed a general enrichment in ethane in the northern hemisphere from winter to spring, whereas our results show constant abundances between these two seasons. The authors also measured an abundance increase for ethane and acetylene at $25^{\circ} \mathrm{N}$, which does not appear in our limb observations. Nevertheless, the hydrocarbons depletion at $15^{\circ} \mathrm{S}$ is present in both observations although it is stronger in our results $(55 \%$ for the limb observations, $17 \%$ for the nadir observations in ethane). Possible calibrations issues have been identified in the nadir datasets acquired in northern spring (L. Fletcher, private communication). Their influence on the retrievals performed by Sinclair et al. (2013) is currently being investigated.

We also compare our results with other observational studies of Saturn's stratosphere. In Sinclair et al. (2014), the authors compared Voyager/IRIS $\left(L_{S}=8^{\circ}, 1980\right)$ and Cassini/CIRS $\left(L_{S}=3^{\circ}\right.$ and $L_{S}=14^{\circ}, 2009$ and 2010), both acquired during northern spring. In the Voyager/IRIS observations, they found a local enrichment in acetylene from $15^{\circ} \mathrm{S}$ to $25^{\circ} \mathrm{S}$ at $2 \mathrm{hPa}$, which is not present in their Cassini/CIRS observations. Our measurement of acetylene mixing ratio at $20^{\circ} \mathrm{S}\left(L_{S}=31^{\circ}\right)$ at $2 \mathrm{hPa}$ is in agreement with the Cassini/CIRS measurements of Sinclair et al. (2014). Sinclair et al. (2014) explained that this difference between Voyager/IRIS and Cassini/CIRS measurements may be due to a different phase of Saturn's equatorial oscillation between these two observations, resulting in a different dynamical forcing at low-latitudes. This explanation is not consistent with our measurements of the seasonal evolution of hydrocarbons abundances. Indeed, we measure few seasonal variations in ethane and acetylene volume mixing ratios at $2 \mathrm{hPa}$, while Guerlet et al. (2011) measured an evolution in the phase of Saturn's equatorial oscillation between 2006 and 2010.

Besides, Greathouse et al. (2005) performed IRTF/TEXES observations in $2002\left(L_{S}=270^{\circ}\right)$ and showed that $\mathrm{C}_{2} \mathrm{H}_{6}$ abundance increases slightly with latitude from equator to south pole at $2 \mathrm{hPa}$. We measure a similar trend from equator to north pole at $2 \mathrm{hPa}$ (see fig. 10) and at $1 \mathrm{hPa}$ (see fig. 9). In Greathouse et al. (2006), the authors also measured a constant propane abundance from $20^{\circ} \mathrm{S}$ to $80^{\circ} \mathrm{S}$ at $5 \mathrm{hPa}$, while our measurements show that propane at $1 \mathrm{hPa}$ (see fig. 9) and at $5 \mathrm{hPa}$ is homogeneously distributed, with a marginal hint of increasing abundances towards the south pole.

\section{Discussion}

\subsection{Comparison of measured temperatures with the pre- dictions of a radiative-convective model}

We use the seasonal radiative-convective model described in Guerlet et al. (2014) to investigate the role of radiative contributions to the seasonal evolution of Saturn's stratospheric thermal structure. This model solves the radiative transfer equations and takes into account vertical and dry convection through parametrizations. Heating and cooling rates are computed including the opacities of $\mathrm{CH}_{4}, \mathrm{C}_{2} \mathrm{H}_{6}, \mathrm{C}_{2} \mathrm{H}_{2}$ and collision-induced absorption by $\mathrm{H}_{2}-\mathrm{H}_{2}$ and $\mathrm{H}_{2}-\mathrm{He}$. Guerlet et al. (2014) represented the radiative contribution of aerosols using two layers of aerosols, constant in latitude and seasons : an optically thick layer in the upper troposphere populated with 
micrometer-size particles, and an optically thin stratospheric layer comprising smaller particles. The effects of Saturn's oblateness and of the shadows of the rings A, $\mathrm{B}$, and $\mathrm{C}$ on the incoming solar flux are included in this model. We use the model in two configurations : in $2 \mathrm{D}$ starting from an equilibrium state, and in 1D, starting from temperature profiles measured in northern winter by Guerlet et al. (2009).

\subsubsection{Comparison of measured temperatures with model predictions}

We run our seasonal radiative-convective model in $2 \mathrm{D}$ (on 128 (latitude) $\times 64$ (altitude) points) during 5 Saturn's years. We start the simulation with a temperature profile obtained from a 1D simulation which reached steady state. We present the predictions of temperature obtained in the last year of this run. Figure 7 presents the comparison between the temperatures predicted by our model with our measurements of the meridional trends of temperature at several pressure levels.

At all pressure levels, for both seasons, the temperatures predicted by the model in the equatorial belt (from $20^{\circ} \mathrm{N}$ to $20^{\circ} \mathrm{S}$ ) do not match well the observed temperatures. For instance, at $1 \mathrm{hPa}$, the measured temperatures show sharp variations around the equator in spring : at $1^{\circ} \mathrm{S}$, the temperature is $133 \pm_{0.9}^{1.1} \mathrm{~K}$ and increases by $7 \pm_{0.9}^{1.1} \mathrm{~K}$ toward $5^{\circ} \mathrm{S}$, and by $5 \pm_{0.9}^{1.1} \mathrm{~K}$ toward $5^{\circ} \mathrm{N}$. In the equatorial belt, at $1 \mathrm{hPa}$, from northern winter to spring, the measured temperatures increase at some latitudes (e.g $15^{\circ} \mathrm{S}$, increase of $8 \pm_{0.9}^{1.1} \mathrm{~K}$ ) and decrease at other latitudes (e.g. $5^{\circ} \mathrm{S}$, decrease of $9 \pm_{0.9}^{1.1} \mathrm{~K}$ ), whereas our model predicts a weak decrease of temperatures of 1-2 $\mathrm{K}$ between $20^{\circ} \mathrm{S}$ and the equator. These differences between the measured and predicted temperatures are expected, as our radiative-convective model can not reproduce temperatures perturbations induced by the equatorial oscillation, which is suggested to be a purely dynamical effect (Fouchet et al., 2008; Guerlet et al., 2011).

In the northern hemisphere (from $25^{\circ} \mathrm{N}$ to $80^{\circ} \mathrm{N}$ ), at $1 \mathrm{hPa}$ and $0.1 \mathrm{hPa}$, the springtime temperatures predicted by the model are in good agreement with the measured temperatures. At both pressure levels, the difference between observed and measured temperature is inferior to $3 \mathrm{~K}$, from $25^{\circ} \mathrm{N}$ to $60^{\circ} \mathrm{N}$. Towards high northern latitudes, the difference between the measured and predicted temperatures increases and reaches for instance $9 \mathrm{~K}$ at $79^{\circ} \mathrm{N}$ at $0.1 \mathrm{hPa}$. Hence, the meridional trend of temperature is well reproduced by our seasonal model from $25^{\circ} \mathrm{N}$ to $60^{\circ} \mathrm{N}$ at $1 \mathrm{hPa}$ and $0.1 \mathrm{hPa}$. At high northern latitudes, Saturn's stratosphere is warmer than expected in the radiative-convective model. In the southern hemisphere (from $25^{\circ} \mathrm{S}$ to $80^{\circ} \mathrm{S}$ ), at $1 \mathrm{hPa}$ and $0.1 \mathrm{hPa}$, the temperature predictions of the model are close to the measurements (within $4 \mathrm{~K}$ ), except at $50^{\circ} \mathrm{S}$, which measured temperature is lower by $6 \mathrm{~K}$ than the prediction of the model. Consequently, in spring the radiative contributions included in our radiative-convective model (dihydrogen, methane, ethane, acetylene, aerosols) can generally explain the temperatures at $1 \mathrm{hPa}$ and $0.1 \mathrm{hPa}$. The temperature contrast between the model and the measurements increases towards high northern latitudes. This might be a hint of the formation of a polar warm hood, similar to what has been observed during summer at high southern latitudes (Orton et al., 2008; Fletcher et al., 2008). As our CIRS limb temperature measurements at $10 \mathrm{hPa}$ and $1 \mathrm{hPa}$ also show that the steep temperature increase towards high southern latitudes disappears, this would support the idea that the appearance of these warm polar regions is seasonal, maybe due to solar absorption by high altitude UV-absorbent polar aerosols, which would enhance the seasonal evolution at the poles (Fletcher et al., 2008, 2015).

In northern winter, at $1 \mathrm{hPa}$ and $0.1 \mathrm{hPa}$, temperature predictions of our radiative convective model are globally in disagreement with the measurements. Under the shadows of the rings, at $25^{\circ} \mathrm{N}$, at $1 \mathrm{hPa}$, the atmosphere is warmer by $12 \mathrm{~K}$ than predicted, whereas temperatures measured at northern mid-latitudes are in good agreement (within $2 \mathrm{~K}$ ) with the model predictions. This strengthens the idea that the perturbation of temperature under the rings is linked to the insolation perturbation induced by the rings shadow (Fouchet et al., 2008; Guerlet et al., 2009). The general circulation model presented by Friedson and Moses (2012) predicts that wintertime subsidence occurring at $25^{\circ} \mathrm{N}$ would be reinforced by the ring shadowing, and that it would counteract the temperature decrease expected radiatively with such a strong insolation variation. However, in the northern hemisphere, at $0.1 \mathrm{hPa}$, measured wintertime temperatures are significantly higher than the predicted temperatures (by at least $6 \mathrm{~K}$ ) at all latitudes (and not only those under the rings shadow) during northern winter. At $1 \mathrm{hPa}$ and $0.1 \mathrm{hPa}$, southern latitudes exhibit summertime temperatures colder than predicted by at least $6 \mathrm{~K}$. These differences show that, contrary to spring, radiative contributions included in the model are not sufficient to explain the temperatures in winter. It also suggests that the influence of dynamics during northern winter would be stronger than during spring. Since the temperature predictions for northern winter mismatch the observed temperatures, the model can not reproduce the measured seasonal evolution at $1 \mathrm{hPa}$ and $0.1 \mathrm{hPa}$.

At $10 \mathrm{hPa}$ and $0.01 \mathrm{hPa}$, predicted temperatures differ from measured temperatures for northern winter and spring. At $10 \mathrm{hPa}$, the meridional distribution of predicted temperatures is in overall agreement with the observations in both hemispheres for both seasons, although the predicted temperatures are lower than the measured temperatures. From $25^{\circ} \mathrm{N}$ to $79^{\circ} \mathrm{N}$, at $10 \mathrm{hPa}$, our radiative convective model predicts a weak seasonal 
contrast ( $\precsim 3 \mathrm{~K})$ consistent with our Cassini/CIRS limb measurements. In the southern hemisphere, the model predicts that the seasonal contrast between southern summer and autumn increases from mid to high latitudes, whereas our measurements exhibit no seasonal contrast at mid-latitudes, then the same seasonal contrast $(8 \mathrm{~K})$ as the model at $70^{\circ} \mathrm{S}$. At $0.01 \mathrm{hPa}$, the observed temperatures are always higher than the predicted temperature. The model predicts large seasonal variations (up to $30 \mathrm{~K}$ ), not consistent with the constant temperature shown by the measurements. This suggests the existence of an additional heat source, active in both seasons, which effect would be stronger than the radiative contributions of atmospheric minor constituents.

\subsubsection{Study of the thermal seasonal evolution}

We perform additional simulations to study in further details the thermal seasonal evolution predicted by the model, and to compare it with the observations. We use our radiative-convective model in 1D (on 64 pressure levels), for several case studies at distinct latitudes. For each latitude, we initialize the simulation with the temperature profile retrieved during northern winter by Guerlet et al. (2009), then we run the model until the next spring (i.e the date of the observations presented in this study). Figure 11 presents the final temperature profiles obtained with these $1 \mathrm{D}$ simulations at $25^{\circ} \mathrm{N}$ and $42^{\circ} \mathrm{S}$, which are representative examples of the results obtained for each hemisphere. They are compared to the temperature profiles from the previous $2 \mathrm{D}$ simulation and to the measured temperature profiles in spring.

At $25^{\circ} \mathrm{N}$, this $1 \mathrm{D}$ simulation yields a better agreement with the springtime measured temperatures below the 1-hPa pressure level than the $2 \mathrm{D}$ simulation of the previous section. For instance, at $10 \mathrm{hPa}$, the temperature predicted by the $1 \mathrm{D}$ simulation is the same as the retrieved temperature in spring, whereas the $2 \mathrm{D}$ simulation prediction is $4 \mathrm{~K}$ colder. From $1 \mathrm{hPa}$ to $0.1 \mathrm{hPa}$, both simulations show results consistent with the measured temperature profile (within $2 \mathrm{~K}$ ). Above the $0.1-\mathrm{hPa}$ pressure level, whereas both simulations predicts similar nearly isothermal profiles, the measured temperature increases with altitude. At $0.01 \mathrm{hPa}$, the $1 \mathrm{D}$ and $2 \mathrm{D}$ simulations predict similar temperatures (in agreement with the low thermal inertia at this pressure level), both 7-8 K colder than the observed temperatures.

At $47^{\circ} \mathrm{S}$, the results of the two simulations are very similar (within $2 \mathrm{~K}$ ), with a slightly better agreement between the $1 \mathrm{D}$ simulation predictions and the observations below the $3-\mathrm{hPa}$ pressure level. From $1 \mathrm{hPa}$ to $0.1 \mathrm{hPa}$, both simulations predict a slight cooling from southern summer to autumn, whereas our measurements do not show any seasonal temperature variations. At $0.1 \mathrm{hPa}$, in southern autumn, both simulations predict temperatures
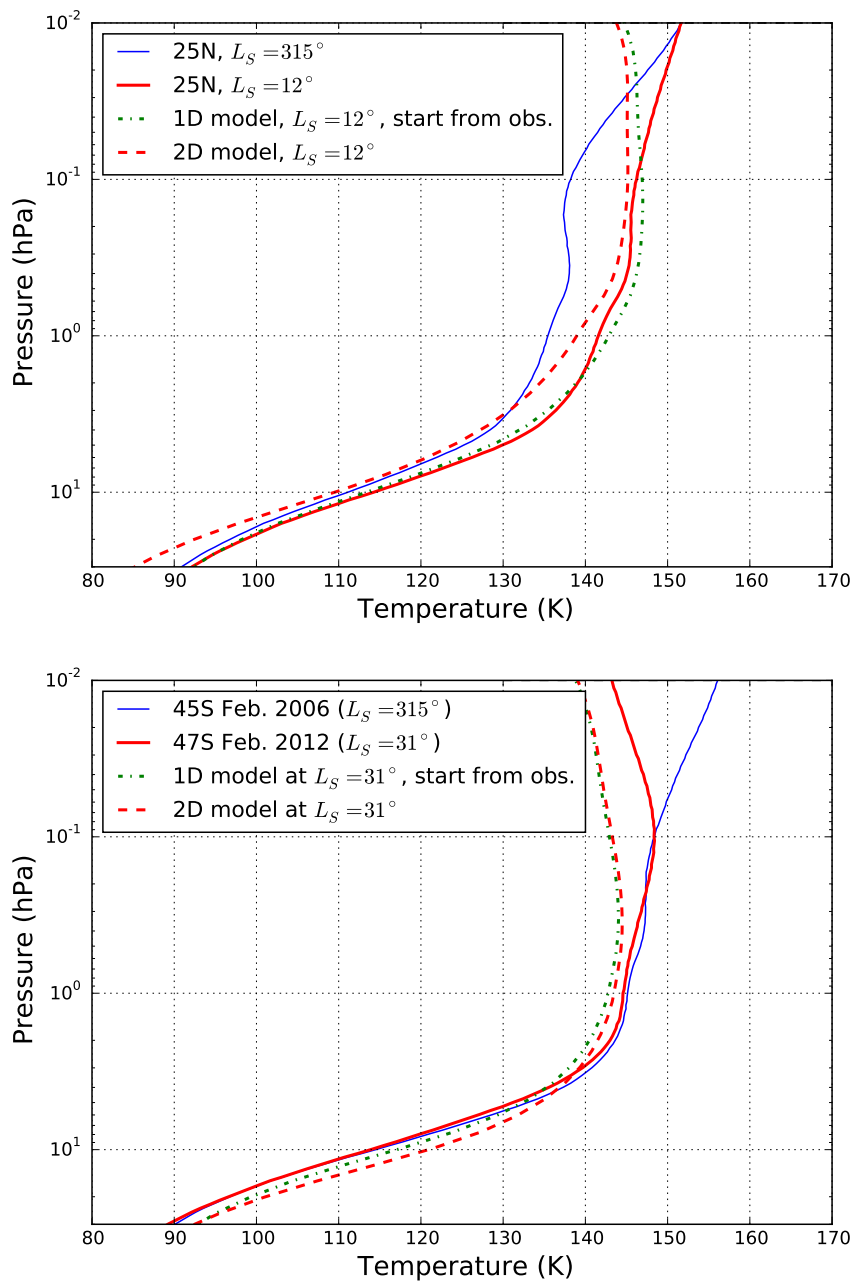

Figure 11: 1D simulations of radiative seasonal evolution. Blue thin solid lines are the measured temperature profiles during winter, used as initial conditions. Red thick solid lines are the measured temperature profiles in spring. Green dot-dashed lines are the temperature profiles obtained in spring, when our radiative model (Guerlet et al., 2014) starts from the observed temperatures. Red dashed lines are temperature profiles predicted by the 2D run for northern spring. Those profiles are shown within the sensitivity limits in pressure of our limb measurements.

of $143 \mathrm{~K}$, whereas a temperature of $147 \pm_{2.0}^{1.5} \mathrm{~K}$ is measured.

We conclude that the disagreement shown in fig. 7 between the measurements and the $2 \mathrm{D}$ simulations at $10 \mathrm{hPa}$ in northern spring, is mainly due to the fact that the model do not reproduce well temperatures in northern winter, and to the longer radiative timescale at this pressure level than at higher pressure levels. That is why $1 \mathrm{D}$ simulations predict better the temperatures up to the 0.1-hPa pressure level. Hence, in the lower stratosphere, the seasonal evolution measured with our Cassini/CIRS limb observations can be accounted for by the radiative contributions of $\mathrm{CH}_{4}, \mathrm{C}_{2} \mathrm{H}_{6}, \mathrm{C}_{2} \mathrm{H}_{2}$ and aerosols. 
In the upper stratosphere, above the $0.1-\mathrm{hPa}$ pressure level, even if the $1 \mathrm{D}$ simulations are initialized with the temperatures observed before vernal equinox, the measured temperatures are still not reproduced by the model. The model even predicts a cooling at $25^{\circ} \mathrm{N}$ for pressures inferior at $0.02 \mathrm{hPa}$, while we observe a heating. This strengthens our conclusion that an additional heat source prevails over the radiative seasonal contributions. We use the $1 \mathrm{D}$ simulations presented above to estimate the heating rate of this additional heat source. We find that this heat source must have a heating rate between $0.004 \mathrm{~K} /$ day and $0.008 \mathrm{~K} /$ day (depending on latitude). It seems unlikely that this would be the effect of the gases neglected in the model. Indeed, Guerlet et al. (2014) showed that radiative contributions of these gases (propane, methylacetylene, diacetylene and $\mathrm{CH}_{3} \mathrm{D}$ ) could lower the predicted temperatures by $1-2 \mathrm{~K}$, which is equivalent to errors on temperature retrievals. It may be due to an additional layer of high stratospheric aerosols, but we lack of observational constraints to model it. Preliminary results from Cassini/UVIS observations seems to indicate that some heat of the thermosphere may diffuse downwards into the upper stratosphere, via molecular heat conduction (D. Strobell, private communication), but the estimation of this heat flux suffers from large uncertainties. Dynamical processes may also be at play. Heating by adiabatic subsidence is unlikely, as it would have to occur at all latitudes. Gravity waves breaking may bring the extra energy needed, as suggested by Yelle et al. (1996) for Jupiter's upper atmosphere. These waves can be triggered by jet instability, or convection, and propagate horizontally and vertically. Their amplitude grows as density decreases. When temperature gradient of the wave reaches the adiabatic lapse rate, convective instability appears. Harrington et al. (2010) probe Saturn's upper stratosphere by stellar occultation, between $0.06 \mathrm{hPa}$ and $0.001 \mathrm{hPa}$. Their measurements of the vertical gradient of temperature show features which they attribute to gravity waves breaking. Harrington et al. (2010) fit their retrieved temperature profile with a gravity wave model and obtain several plausible gravity wave detections. We use the characteristics of their detected waves (period, vertical wavelength, and temperature amplitude) to compute the energy flux those waves transport, using the formula derived by French and Gierasch (1974) and the correction brought by Matcheva and Strobel (1999) :

$$
F=\frac{\omega}{\mu} \frac{\rho_{0} c_{p}\left(\Delta T_{1}\right)^{2}}{T_{0}} \frac{1-\frac{\omega^{2}}{N^{2}}}{1+\frac{1}{\mu^{2} H^{2}}\left(\frac{1}{2}-\frac{\gamma-1}{\gamma} \frac{\omega^{2}}{N^{2}}\right)^{2}}
$$

a function of thermodynamic parameters (with $\gamma$ the adiabatic coefficient, $c_{p}$ the specific heat at constant pressure), local atmospheric parameters ( $\rho_{0}$ the density, $T_{0}$ the background temperature, $N$ the Brunt-Väisälä frequency, $\mathrm{H}$ the scale height), and wave characteristics ( $\mu$ the verti- cal wavenumber, $\omega$ the pulsation, $\Delta T_{1}$ the temperature amplitude). Equation 1 describes the vertical energy flux transported by hydrostatic gravity waves in a compressible atmosphere. We assume that the vertical direction is the dominant direction of propagation because when there is wave breaking, the atmosphere becomes locally buoyantly unstable and generates vertical mixing. Vertical scales (vertical wavelength and pressure scale height) are also much smaller than the horizontal scale. The heating rate produced by the breaking of these waves is approximately:

$$
\frac{d T}{d t}=\frac{d F}{d z} \frac{1}{\rho c_{p}} \sim \frac{F}{H} \frac{1}{\rho c_{p}}
$$

Using these formulas and the characteristics of the waves detected by Harrington et al. (2010), we find that the breaking of such waves at $0.01 \mathrm{hPa}$ can produce a heating rate at least $0.002 \mathrm{~K} /$ day and up to $0.13 \mathrm{~K} /$ day. Hence, gravity wave breaking could bring the additional energy needed to explain the observed temperatures at $0.01 \mathrm{hPa}$. The large range of heating rates found is explained by the diversity of the characteristics of waves detected by Harrington et al. (2010). Indeed, their thermal amplitudes vary between $0.26 \mathrm{~K}$ and $1 \mathrm{~K}$, their vertical wavelengths from $6.5 \mathrm{~km}$ to $40 \mathrm{~km}$, and their periods from 13.3 minutes to 125.7 minutes. Thus, further characterization of gravity waves in Saturn's atmosphere is highly needed to estimate more accurately the energy transported and deposited by these waves in the upper stratosphere. Besides, breaking has to occur at $0.01 \mathrm{hPa}$, whereas the model of Matcheva and Barrow (2012) predicts that the region of wave dissipation is $\left[10^{-5} ; 10^{-8}\right] \mathrm{hPa}$ for a large range of gravity waves parameters. The vertical shear of zonal winds would maybe help to trigger gravity waves breaking as low as $0.01 \mathrm{hPa}$, but this shear in the upper stratosphere is yet to be measured.

\subsection{Comparison of measured hydrocarbons abundances with a photochemical model}

In fig. 9, the retrieved abundances of the hydrocarbons are compared with the predictions of the photochemical model of Moses and Greathouse (2005). It is a 1D seasonal model which takes into account vertical eddy and molecular diffusion and rings shadowing, but does not include any horizontal redistribution of hydrocarbon species.

At $1 \mathrm{hPa}$, our observations of ethane, acetylene and propane exhibit little seasonal variations in abundance as predicted by the photochemical model. Indeed, at this pressure level, their photochemical timescales are superior to one Saturn's year, thus the abundances of these species are not expected to follow the seasonal variations of insolation. However, at $1 \mathrm{hPa}$, the model of 
Moses and Greathouse (2005) also predicts that hydrocarbons abundances are mainly controlled by the yearly averaged insolation, so that the hydrocarbons abundances decrease from equator to poles. Our measurements and those of Guerlet et al. (2009) show that ethane and propane do not follow this predicted meridional trend, and are homogeneously distributed in latitudes, whereas the meridional distribution of acetylene abundance is well reproduced by the model. This supports the idea of a meridional circulation (proposed by Howett et al. (2007); Hesman et al. (2009); Guerlet et al. (2009)) transporting the hydrocarbons on a timescale longer than the acetylene photochemical loss timescale (3 years, Moses and Greathouse (2005)), but shorter than ethane (634 years, Moses and Greathouse (2005)), and propane net photochemical time constants (difference between photochemical loss and production timescales). Assuming that the timescale of this meridional circulation is the photochemical net timescale of ethane, the meridional mixing coefficient at $1 \mathrm{hPa}$ would be $K_{y y}=4.5 \times 10^{9} \mathrm{~cm}^{2} / \mathrm{s}$, which is lower than the meridional mixing coefficient of Jupiter $\left(K_{y y}=2-5 \times 10^{11} \mathrm{~cm}^{2} / \mathrm{s}\right.$, Moreno et al. (2003); Griffith et al. (2004)) in the $0.5-1 \mathrm{hPa}$ region. Even if the predicted meridional distribution of ethane mismatch the observations, its measured abundances are of the same order of magnitude as the predicted abundances. Conversely, measured propane mixing ratios are significantly higher than the predictions (e.g by a factor $\sim 33$ at $79^{\circ} \mathrm{N}$ ), implying that some reactions producing propane may be missing in the model, or that the kinetics of the loss and production reactions of propane may not be fully understood.

At $0.1 \mathrm{hPa}$ and $0.01 \mathrm{hPa}$, the measured abundances of ethane and acetylene exhibit few seasonal variations. The measured meridional distribution of these hydrocarbons is asymmetric at $0.1 \mathrm{hPa}$ and $0.01 \mathrm{hPa}$ (with lower abundances in the southern hemisphere than in the northern hemisphere). The predicted abundances of ethane and acetylene are close within error bars to the measurements in the northern hemisphere, but significantly lower in the southern hemisphere (e.g by a factor 3.3 at $35^{\circ} \mathrm{S}$ at $0.01 \mathrm{hPa}$ ) for both seasons. At $0.01 \mathrm{hPa}$, the measured trends are even opposite to the trends predicted by photochemical modelling, as the model outputs show a decrease from southern to northern hemisphere. Guerlet et al. (2009) noticed this asymmetry in their limb measurements of $\mathrm{C}_{2} \mathrm{H}_{6}$ and $\mathrm{C}_{2} \mathrm{H}_{2}$ (northern winter) and interpreted it as an effect of a strong meridional circulation from the summer to the winter hemisphere. Hence, one would expect that the hydrocarbons meridional distributions would change at the next season, which is not what our observations show. However, Moses and Greathouse (2005) showed that the combination of the vertical diffusion timescale and the photochemical lifetimes can introduce phase lag in the seasonal mixing ratios variations. Thus, the meridional circulation proposed by
Guerlet et al. (2009) may have stopped in spring, even if it is not yet reflected by the hydrocarbons meridional trends.

In section 3 , we present a local maximum in acetylene and ethane abundances around $25^{\circ} \mathrm{N}$, at $0.01 \mathrm{hPa}$, observed in northern winter, which has disappeared in spring. Fig. 9 shows that the photochemical model predicts the opposite behaviour in spring, i.e an enrichment in hydrocarbons at this latitude. The local wintertime maximum at $25^{\circ} \mathrm{N}$ is interpreted as an evidence for local subsidence under the shadows of the rings (Guerlet et al., 2009), related to a seasonally reversing Hadley cell (Friedson and Moses, 2012). We propose that this seasonal subsidence has stopped in spring, and that the local maximum has spread under the effect of vertical diffusion. Indeed, the typical timescale for vertical diffusion is 0.6 years at $0.01 \mathrm{hPa}$ (Moses and Greathouse, 2005), while our observations and those of Guerlet et al. (2009) are separated by $\sim 5$ years.

\section{Conclusion}

We present temperature and hydrocarbons abundances $\left(\mathrm{C}_{2} \mathrm{H}_{6}, \mathrm{C}_{2} \mathrm{H}_{2}, \mathrm{C}_{3} \mathrm{H}_{8}\right)$ retrieved from Cassini/CIRS limb observations performed during northern spring. We have compared them to the previous limb measurements performed by Guerlet et al. (2009) during northern winter. These observations allow us to monitor the seasonal evolution of Saturn's thermal stratospheric structure in both hemispheres. We find a puzzling asymmetric evolution of temperatures in the two hemispheres. In the northern hemisphere (from $25^{\circ} \mathrm{N}$ to $80^{\circ} \mathrm{N}$ ), the seasonal thermal contrast is maximal around $1 \mathrm{hPa}$ and decreases towards lower pressures. The southern hemisphere exhibits several trends of seasonal evolution. The temperature is approximately constant from southern summer to autumn at mid-latitudes from $10 \mathrm{hPa}$ to $0.1 \mathrm{hPa}$. At lower pressures, southern mid-latitudes cools strongly. At $70^{\circ} \mathrm{S}$, the seasonal evolution is different as the stratosphere has cooled by $12 \mathrm{~K}$ at every probed pressure levels $([10 ; 0.01] \mathrm{hPa})$. However, the comparison of our limb measurements of temperature with the nadir results for temperatures of Fletcher et al. (2010) in southern autumn, shows a disagreement at the southern mid-latitudes $\left(42^{\circ} \mathrm{S}\right.$ and $\left.47^{\circ} \mathrm{S}\right)$ at $2 \mathrm{hPa}$, which indicates that these latitudes may be prone to a local phenomenon (e.g thermal signature of atmospheric waves), unresolved by our limb observations of February 2012. Consequently, the temperature variations measured at these latitudes may not be representative of the seasonal evolution of the southern hemisphere. Besides, we compare our Cassini/CIRS limb measurements and those of Guerlet et al. (2009) with our radiative-convective model (Guerlet et al., 2014). In the lower stratosphere (from $10 \mathrm{hPa}$ to $0.1 \mathrm{hPa}$ ), temperatures in northern spring are well reproduced by this model, indicating that they can be 
accounted for by radiative contributions of $\mathrm{H}_{2}$ collisions induced emission, methane, ethane, acetylene and aerosols. Conversely, measured upper stratospheric temperatures (at both seasons) are significantly higher than in the model predictions, implying that other processes are at play at this altitude. We show that gravity waves breaking may bring enough heat to get these temperatures at $0.01 \mathrm{hPa}$, but further observational characterization of these waves are needed, as the energy they transport is strongly dependent of their characteristics (vertical wavelength, period...). The temperatures predicted by the radiative convective model during northern winter mismatch the measured temperature at all pressure levels. This could mean that interhemispheric atmospheric circulation is stronger in winter than in spring.

We also investigate the seasonal evolution of byproducts of methane photochemistry : ethane, acetylene and propane. Our measurements show that the abundances of these hydrocarbons do not exhibit any seasonal variations at $1 \mathrm{hPa}$, consistently with their photochemical timescales, largely superior to Saturn's year at this pressure level. The comparison of the meridional distributions of these three hydrocarbons at $1 \mathrm{hPa}$ with the photochemical model of Moses and Greathouse (2005) suggests the existence of a meridional circulation in the lower stratosphere, which can explain the homogeneous meridional distribution of ethane and propane. This meridional circulation would occur on a timescale between 190 years and 634 years, which are the respective photochemical net time constants of acetylene and ethane. In the upper stratosphere, at $0.01 \mathrm{hPa}$, the local hydrocarbons enhancement around $25^{\circ} \mathrm{N}$, attributed to wintertime subsidence under the rings shadow has disappeared in spring. This could be accounted for by a seasonal evolution in atmospheric circulation : the subsidence at $25^{\circ} \mathrm{N}$ would have stopped in spring and the local maximum in hydrocarbons abundances would have been spread by vertical diffusion.

Subtle coupling between radiative effects, photochemistry and dynamics are at play in Saturn's stratosphere. Further investigations with a GCM (Global Climate Model) should help to understand how the seasonal insolation variations affects the atmospheric circulation. As the Cassini mission is extended until 2017 (northern summer solstice), next limb and nadir observations of the stratosphere will allow us to monitor its seasonal evolution. Further temperature measurements will bring new constraints on the seasonal thermal evolution of the southern hemisphere. As the rings shadow extends on the southern hemisphere, it will be possible to compare its impact on hydrocarbons abundances and temperatures, and their seasonal evolution with those of the northern hemisphere during winter, to disentangle local phenomena and global seasonal variations.

\section{Acknowlegements}

M. Sylvestre, A. Spiga and T. Fouchet aknowledge funding by the Émergence Program of UPMC. S. Guerlet acknowledges funding by the French ANR under grant agreement ANR-12-PDOC-0013. Part of this work was also funded by the Institut Universitaire de France. We also thank D. Strobel for his suggestions about the heating processes of the upper stratosphere, the Cassini/CIRS team for their calibration and planning of the data, and the reviewers for their constructive comments on this paper.

\section{References}

Bézard, B., Gautier, D., Feb. 1985. A seasonal climate model of the atmospheres of the giant planets at the Voyager encounter time. I - Saturn's stratosphere. Icarus61, 296-310.

Borysow, A., Frommhold, L., May 1986. Theoretical collisioninduced rototranslational absorption spectra for the outer planets - H2-CH4 pairs. ApJ304, 849-865.

Borysow, J., Frommhold, L., Birnbaum, G., Mar. 1988. Collisoninduced rototranslational absorption spectra of $\mathrm{H} 2-\mathrm{He}$ pairs at temperatures from 40 to $3000 \mathrm{~K}$. ApJ326, 509-515.

Borysow, J., Trafton, L., Frommhold, L., Birnbaum, G., Sep. 1985. Modeling of pressure-induced far-infrared absorption spectra Molecular hydrogen pairs. ApJ296, 644-654.

Carlson, B. E., Caldwell, J., Cess, R. D., Aug. 1980. A model of Saturn's seasonal stratosphere at the time of the Voyager encounters. Journal of Atmospheric Sciences 37, 1883-1885.

Conor A. Nixon, Monte S. Kaelberer, N. G., Team, T. C. I., 2012. Cirs user guide. Tech. rep., NASA GSFC.

URL http://pds-atmospheres.nmsu.edu/data_and_services/ atmospheres_data/Cassini/cirs.html

Conrath, B. J., Gautier, D., Mar. 2000. Saturn Helium Abundance: A Reanalysis of Voyager Measurements. Icarus144, 124-134.

Courtin, R., Gautier, D., Marten, A., Bezard, B., Hanel, R., Dec. 1984. The composition of Saturn's atmosphere at northern temperate latitudes from Voyager IRIS spectra - NH3, PH3, $\mathrm{C} 2 \mathrm{H} 2, \mathrm{C} 2 \mathrm{H} 6, \mathrm{CH} 3 \mathrm{D}, \mathrm{CH} 4$, and the Saturnian D/H isotopic ratio. ApJ287, 899-916.

Flasar, F. M., Achterberg, R. K., Conrath, B. J., Pearl, J. C., Bjoraker, G. L., Jennings, D. E., Romani, P. N., Simon-Miller, A. A., Kunde, V. G., Nixon, C. A., Bézard, B., Orton, G. S., Spilker, L. J., Spencer, J. R., Irwin, P. G. J., Teanby, N. A., Owen, T. C., Brasunas, J., Segura, M. E., Carlson, R. C., Mamoutkine, A., Gierasch, P. J., Schinder, P. J., Showalter, M. R., Ferrari, C., Barucci, A., Courtin, R., Coustenis, A., Fouchet, T., Gautier, D., Lellouch, E., Marten, A., Prangé, R., Strobel, D. F., Calcutt, S. B., Read, P. L., Taylor, F. W., Bowles, N., Samuelson, R. E., Abbas, M. M., Raulin, F., Ade, P., Edgington, S., Pilorz, S., Wallis, B., Wishnow, E. H., Feb. 2005. Temperatures, Winds, and Composition in the Saturnian System. Science 307, 1247-1251.

Flasar, F. M., Kunde, V. G., Abbas, M. M., Achterberg, R. K., Ade, P., Barucci, A., Bézard, B., Bjoraker, G. L., Brasunas, J. C., Calcutt, S., Carlson, R., Césarsky, C. J., Conrath, B. J., Coradini, A., Courtin, R., Coustenis, A., Edberg, S., Edgington, S., Ferrari, C., Fouchet, T., Gautier, D., Gierasch, P. J., Grossman, K., Irwin, P., Jennings, D. E., Lellouch, E., Mamoutkine, A. A., Marten, A., Meyer, J. P., Nixon, C. A., Orton, G. S., Owen, T. C., Pearl, J. C., Prangé, R., Raulin, F., Read, P. L., Romani, P. N., Samuelson, R. E., Segura, M. E., Showalter, M. R., Simon-Miller, A. A., Smith, M. D., Spencer, J. R., Spilker, L. J., Taylor, F. W., Dec. 2004. Exploring The Saturn System In The Thermal Infrared: The Composite Infrared Spectrometer. Space Sci. Rev.115, 169-297.

Flasar, F. M., Schinder, P. J., Achterberg, R. K., Conrath, B. J., Cassini/CIRS Investigation Team, Cassini/RSS Team, Sep. 2008. On Combining Thermal-infrared And Radio-occultation Data Of 
Saturn's And Titan's Atmospheres. In: AAS/Division for Planetary Sciences Meeting Abstracts \#40. Vol. 40 of Bulletin of the American Astronomical Society. p. 495.

Fletcher, L. N., Achterberg, R. K., Greathouse, T. K., Orton, G. S., Conrath, B. J., Simon-Miller, A. A., Teanby, N., Guerlet, S., Irwin, P. G. J., Flasar, F. M., Jul. 2010. Seasonal change on Saturn from Cassini/CIRS observations, 2004-2009. Icarus208, 337-352.

Fletcher, L. N., Hesman, B. E., Achterberg, R. K., Irwin, P. G. J., Bjoraker, G., Gorius, N., Hurley, J., Sinclair, J., Orton, G. S., Legarreta, J., García-Melendo, E., Sánchez-Lavega, A., Read, P. L., Simon-Miller, A. A., Flasar, F. M., Nov. 2012. The origin and evolution of Saturn's 2011-2012 stratospheric vortex. Icarus221, 560-586

Fletcher, L. N., Irwin, P. G. J., Orton, G. S., Teanby, N. A., Achterberg, R. K., Bjoraker, G. L., Read, P. L., Simon-Miller, A. A. Howett, C., de Kok, R., Bowles, N., Calcutt, S. B., Hesman, B., Flasar, F. M., Jan. 2008. Temperature and Composition of Saturn's Polar Hot Spots and Hexagon. Science 319, 79-.

Fletcher, L. N., Irwin, P. G. J., Sinclair, J. A., Orton, G. S., Giles, R. S., Hurley, J., Gorius, N., Achterberg, R. K., Hesman, B. E., Bjoraker, G. L., Apr. 2015. Seasonal evolution of Saturn's polar temperatures and composition. Icarus250, 131-153.

Fletcher, L. N., Irwin, P. G. J., Teanby, N. A., Orton, G. S., Parrish, P. D., de Kok, R., Howett, C., Calcutt, S. B., Bowles, N., Taylor, F. W., Aug. 2007. Characterising Saturn's vertical temperature structure from Cassini/CIRS. Icarus189, 457-478.

Fouchet, T., Guerlet, S., Strobel, D. F., Simon-Miller, A. A., Bézard, B., Flasar, F. M., May 2008. An equatorial oscillation in Saturn's middle atmosphere. Nature453, 200-202.

French, R. G., Gierasch, P. J., Sep. 1974. Waves in the Jovian Upper Atmosphere. Journal of Atmospheric Sciences 31, 1707-1712.

Friedson, A. J., Moses, J. I., Apr. 2012. General circulation and transport in Saturn's upper troposphere and stratosphere. Icarus218, 861-875.

Greathouse, T. K., Lacy, J. H., Bézard, B., Moses, J. I., Griffith, C. A., Richter, M. J., Sep. 2005. Meridional variations of temperature, $\mathrm{C}_{2} \mathrm{H}_{2}$ and $\mathrm{C}_{2} \mathrm{H}_{6}$ abundances in Saturn's stratosphere at southern summer solstice. Icarus177, 18-31.

Greathouse, T. K., Lacy, J. H., Bézard, B., Moses, J. I., Richter, M. J., Knez, C., Mar. 2006. The first detection of propane on Saturn. Icarus181, 266-271.

Griffith, C. A., Bézard, B., Greathouse, T., Lellouch, E., Lacy, J., Kelly, D., Richter, M. J., Jul. 2004. Meridional transport of HCN from SL9 impacts on Jupiter. Icarus170, 58-69.

Guerlet, S., Fouchet, T., Bézard, B., Flasar, F. M., Simon-Miller, A. A., May 2011. Evolution of the equatorial oscillation in Saturn's stratosphere between 2005 and 2010 from Cassini/CIRS limb data analysis. Geophys. Res. Lett.38, 9201.

Guerlet, S., Fouchet, T., Bézard, B., Simon-Miller, A. A., Michael Flasar, F., Sep. 2009. Vertical and meridional distribution of ethane, acetylene and propane in Saturn's stratosphere from CIRS/Cassini limb observations. Icarus203, 214-232.

Guerlet, S., Spiga, A., Sylvestre, M., Indurain, M., Fouchet, T. Leconte, J., Millour, E., Wordsworth, R., Capderou, M., Bézard, B., Forget, F., Aug. 2014. Global climate modeling of Saturn's atmosphere. Part I: Evaluation of the radiative transfer model. Icarus238, 110-124

Hanel, R., Conrath, B., Flasar, F. M., Kunde, V., Maguire, W., Pearl, J. C., Pirraglia, J., Samuelson, R., Herath, L., Allison, M., Cruikshank, D. P., Gautier, D., Gierasch, P. J., Horn, L., Koppany, R., Ponnamperuma, C., Apr. 1981. Infrared observations of the Saturnian system from Voyager 1. Science 212, 192-200.

Harrington, J., French, R. G., Matcheva, K., Jun. 2010. The 1998 November 14 Occultation of GSC 0622-00345 by Saturn. II. Stratospheric Thermal Profile, Power Spectrum, and Gravity Waves. ApJ716, 404-416

Hesman, B. E., Jennings, D. E., Sada, P. V., Bjoraker, G. L., Achterberg, R. K., Simon-Miller, A. A., Anderson, C. M., Boyle, R. J., Nixon, C. A., Fletcher, L. N., McCabe, G. H., Jul. 2009. Saturn's latitudinal $\mathrm{C}_{2} \mathrm{H}_{2}$ and $\mathrm{C}_{2} \mathrm{H}_{6}$ abundance profiles from Cassini/CIRS and ground-based observations. Icarus202, 249-259.
Howett, C. J. A., Irwin, P. G. J., Teanby, N. A., Simon-Miller, A., Calcutt, S. B., Fletcher, L. N., de Kok, R., Oct. 2007. Meridional variations in stratospheric acetylene and ethane in the southern hemisphere of the saturnian atmosphere as determined from Cassini/CIRS measurements. Icarus190, 556-572.

Jacquinet-Husson, N., Scott, N. A., Chédin, A., Crépeau, L., Armante, R., Capelle, V., Orphal, J., Coustenis, A., Boonne, C., Poulet-Crovisier, N., Barbe, A., Birk, M., Brown, L. R., CamyPeyret, C., Claveau, C., Chance, K., Christidis, N., Clerbaux, C., Coheur, P. F., Dana, V., Daumont, L., De Backer-Barilly, M. R., Di Lonardo, G., Flaud, J. M., Goldman, A., Hamdouni, A., Hess, M., Hurley, M. D., Jacquemart, D., Kleiner, I., Köpke, P., Mandin, J. Y., Massie, S., Mikhailenko, S., Nemtchinov, V., Nikitin, A., Newnham, D., Perrin, A., Perevalov, V. I., Pinnock, S., RégaliaJarlot, L., Rinsland, C. P., Rublev, A., Schreier, F., Schult, L., Smith, K. M., Tashkun, S. A., Teffo, J. L., Toth, R. A., Tyuterev, V. G., Vander Auwera, J., Varanasi, P., Wagner, G., Apr. 2008. The GEISA spectroscopic database: Current and future archive for Earth and planetary atmosphere studies. J. Quant. Spec. Radiat. Transf.109, 1043-1059.

Jacquinet-Husson, N., Scott, N. A., Chédin, A., Garceran, K., Armante, R., Chursin, A. A., Barbe, A., Birk, M., Brown, L. R. Camy-Peyret, C., Claveau, C., Clerbaux, C., Coheur, P. F., Dana, V., Daumont, L., Debacker-Barilly, M. R., Flaud, J. M., Goldman, A., Hamdouni, A., Hess, M., Jacquemart, D., Köpke, P., Mandin, J. Y., Massie, S., Mikhailenko, S., Nemtchinov, V., Nikitin, A. Newnham, D., Perrin, A., Perevalov, V. I., Régalia-Jarlot, L., Rublev, A., Schreier, F., Schult, I., Smith, K. M., Tashkun, S. A., Teffo, J. L., Toth, R. A., Tyuterev, V. G., Vander Auwera, J., Varanasi, P., Wagner, G., Nov. 2005. The 2003 edition of the GEISA/IASI spectroscopic database. J. Quant. Spec. Radiat. Transf.95, 429-467.

Lellouch, E., Bézard, B., Fouchet, T., Feuchtgruber, H., Encrenaz, T., de Graauw, T., May 2001. The deuterium abundance in Jupiter and Saturn from ISO-SWS observations. A\&A370, 610622

Lindal, G. F., Sweetnam, D. N., Eshleman, V. R., Jun. 1985. The atmosphere of Saturn - an analysis of the Voyager radio occultation measurements. AJ90, 1136-1146.

Matcheva, K. I., Barrow, D. J., Nov. 2012. Small-scale variability in Saturn's lower ionosphere. Icarus221, 525-543.

Matcheva, K. I., Strobel, D. F., Aug. 1999. Heating of Jupiter's Thermosphere by Dissipation of Gravity Waves Due to Molecular Viscosity and Heat Conduction. Icarus140, 328-340.

Moreno, R., Marten, A., Matthews, H. E., Biraud, Y., Aug. 2003. Long-term evolution of CO, CS and HCN in Jupiter after the impacts of comet Shoemaker-Levy 9. Planet. Space Sci.51, 591611

Moses, J., Vervack, Jr., R. J., Sep. 2006. Saturn's Upper Atmospheric Structure: Forward Modeling and Comparison with a Reanalysis of the Voyager UVS Occultation Data. In: AAS/Division for Planetary Sciences Meeting Abstracts \#38. Vol. 38 of Bulletin of the American Astronomical Society. p. 500

Moses, J. I., Bézard, B., Lellouch, E., Gladstone, G. R., Feuchtgruber, H., Allen, M., Feb. 2000. Photochemistry of Saturn's Atmosphere. I. Hydrocarbon Chemistry and Comparisons with ISO Observations. Icarus143, 244-298.

Moses, J. I., Greathouse, T. K., Sep. 2005. Latitudinal and seasonal models of stratospheric photochemistry on Saturn: Comparison with infrared data from IRTF/TEXES. Journal of Geophysical Research (Planets) 110, 9007.

Orton, G. S., Yanamandra-Fisher, P. A., Feb. 2005. Saturn's Temperature Field from High-Resolution Middle-Infrared Imaging. Science 307, 696-698.

Orton, G. S., Yanamandra-Fisher, P. A., Fisher, B. M., Friedson, A. J., Parrish, P. D., Nelson, J. F., Bauermeister, A. S., Fletcher, L., Gezari, D. Y., Varosi, F., Tokunaga, A. T., Caldwell, J., Baines, K. H., Hora, J. L., Ressler, M. E., Fujiyoshi, T., Fuse, T., Hagopian, H., Martin, T. Z., Bergstralh, J. T., Howett, C., Hoffmann, W. F., Deutsch, L. K., van Cleve, J. E., Noe, E., Adams, J. D., Kassis, M., Tollestrup, E., May 2008. Semi-annual 
oscillations in Saturn's low-latitude stratospheric temperatures. Nature453, 196-199.

Rodgers, C. D., 2000. Inverse Methods for Atmospheric Sounding Theory and Practice. Inverse Methods for Atmospheric Sounding Theory and Practice. Series: Series on Atmospheric Oceanic and Planetary Physics, ISBN: 9789812813718. World Scientific Publishing Co. Pte. Ltd., Edited by Clive D. Rodgers, vol. 22.

Sánchez-Lavega, A., del Río-Gaztelurrutia, T., Delcroix, M., Legarreta, J. J., Gómez-Forrellad, J. M., Hueso, R., García-Melendo, E. Pérez-Hoyos, S., Barrado-Navascués, D., Lillo, J., International Outer Planet Watch Team IOPW-PVOL, Aug. 2012. Groundbased observations of the long-term evolution and death of Saturn's 2010 Great White Spot. Icarus220, 561-576.

Sinclair, J. A., Irwin, P. G. J., Fletcher, L. N., Greathouse, T., Guerlet, S., Hurley, J., Merlet, C., May 2014. From Voyager-IRIS to Cassini-CIRS: Interannual variability in Saturn's stratosphere? Icarus233, 281-292.

Sinclair, J. A., Irwin, P. G. J., Fletcher, L. N., Moses, J. I., Greathouse, T. K., Friedson, A. J., Hesman, B., Hurley, J., Merlet, C., Jul. 2013. Seasonal variations of temperature, acetylene and ethane in Saturn's atmosphere from 2005 to 2010, as observed by Cassini-CIRS. Icarus225, 257-271.

Yelle, R. V., Young, L. A., Vervack, R. J., Young, R., Pfister, L., Sandel, B. R., 1996. Structure of Jupiter's upper atmosphere: Predictions for Galileo. J. Geophys. Res.101, 2149-2162. 